NBER WORKING PAPER SERIES

\title{
CASH AND THE ECONOMY: EVIDENCE FROM INDIA'S DEMONETIZATION
}

\author{
Gabriel Chodorow-Reich \\ Gita Gopinath \\ Prachi Mishra \\ Abhinav Narayanan \\ Working Paper 25370 \\ http://www.nber.org/papers/w25370 \\ NATIONAL BUREAU OF ECONOMIC RESEARCH \\ 1050 Massachusetts Avenue \\ Cambridge, MA 02138 \\ December 2018
}

We thank Martin Rama and Robert Carl Michael Beyer of the World Bank for sharing night lights data, Tilottama Ghosh at the Earth Observation Group at NOAA for clarifying many basic questions relating to the nightlights data, National Payments Corporation of India for providing data on ATM and POS transactions, and Quantta for providing geocode coordinates. We thank Fernando Alvarez (discussant), Pol Antras (editor), Vimal Balasubramaniam (discussant), Robert Barro (editor), Bent Sorenson (discussant), four anonymous referees, and numerous seminar participants for their comments. Gabriel Konigsberg and Anna Stansbury provided excellent research assistance. Gita Gopinath is Economic Counselor and Director of Research at the IMF. She completed this work before joining the IMF, when she was Professor at Harvard. Ms. Mishra was employed at the IMF at the time this work was completed. The views expressed herein are those of the authors and not necessarily those of the Reserve Bank of India, Goldman Sachs, the International Monetary Fund, or any other institution with which the authors are affliated. The views expressed herein are those of the authors and do not necessarily reflect the views of the National Bureau of Economic Research.

NBER working papers are circulated for discussion and comment purposes. They have not been peerreviewed or been subject to the review by the NBER Board of Directors that accompanies official NBER publications.

(C) 2018 by Gabriel Chodorow-Reich, Gita Gopinath, Prachi Mishra, and Abhinav Narayanan. All rights reserved. Short sections of text, not to exceed two paragraphs, may be quoted without explicit permission provided that full credit, including $\odot$ notice, is given to the source. 
Cash and the Economy: Evidence from India's Demonetization

Gabriel Chodorow-Reich, Gita Gopinath, Prachi Mishra, and Abhinav Narayanan

NBER Working Paper No. 25370

December 2018, Revised May 2019

JEL No. E5,O23

\begin{abstract}
$\underline{\text { ABSTRACT }}$
We analyze a unique episode in the history of monetary economics, the 2016 Indian "demonetization." This policy made $86 \%$ of cash in circulation illegal tender overnight, with new notes gradually introduced over the next several months. We present a model of demonetization where agents hold cash both to satisfy a cash-in-advance constraint and for tax evasion purposes. We test the predictions of the model in the cross-section of Indian districts using several novel data sets including: the geographic distribution of demonetized and new notes for causal inference; nightlight activity and employment surveys to measure economic activity including in the informal sector; debit/credit cards and e-wallet transactions data; and banking data on deposit and credit growth. Districts experiencing more severe demonetization had relative reductions in economic activity, faster adoption of alternative payment technologies, and lower bank credit growth. The cross-sectional responses cumulate to a contraction in employment and nightlights-based output due to demonetization of 2 p.p. and of bank credit of 2 p.p. in 2016Q4 relative to their counterfactual paths, effects which dissipate over the next few months. These cumulated effects provide a lower bound for the aggregate effects of demonetization. Our analysis rejects money non-neutrality using a large scale natural experiment, something that is yet rare in the vast literature on the effects of monetary policy.
\end{abstract}

\author{
Gabriel Chodorow-Reich \\ Department of Economics \\ Harvard University \\ 1805 Littauer Center \\ Cambridge, MA 02138 \\ and NBER \\ chodorowreich@fas.harvard.edu \\ Gita Gopinath \\ Department of Economics \\ Harvard University \\ 1875 Cambridge Street \\ Littauer 206 \\ Cambridge, MA 02138 \\ and NBER \\ gopinath@harvard.edu
}

\author{
Prachi Mishra \\ Global Macro Research \\ Goldman Sachs, Mumbai \\ Prachi.mishra@gs.com \\ Abhinav Narayanan \\ abhinavnarayanan@rbi.org.in
}




\section{Introduction}

Despite an impressive body of literature on the effects of monetary policy, large scale natural experiments remain rare. In this paper we study a unique episode known as demonetization. On November 8th, 2016, the government of India unexpectedly declared $86 \%$ of the existing currency in circulation illegal tender, effective at midnight. Printing press constraints prevented the immediate replacement of the demonetized currency with new notes, with the result that cash that could be used in transactions declined sharply. Moreover, the arrival rate of new currency notes varied tremendously across geographic areas. Demonetization occurred in an otherwise stable macroeconomic environment and did not affect other hallmarks of monetary policy such as the overall liabilities of the Reserve Bank of India (RBI) or the target interest rate.

We have two main findings. First, we reject money neutrality by providing well-identified, statistically strong evidence of an effect of money on output in the cross-section of Indian districts. Second, we shed light on why cash matters. In the New Keynesian synthesis (Woodford, 2003), money serves only as a unit of account and outcomes depend only on the interest rate set by monetary policy, with the details of the money supply essentially irrelevant. During demonetization, cash declined while the sum of cash and checking deposits remained stable and market interest rates changed little. We therefore conclude that in modern India cash plays a special role in facilitating transactions.

We first present a model of demonetization to guide the empirical analysis. In the model, agents hold cash for two reasons. Firstly, because of a cash-in-advance (CIA) constraint requiring money holdings to pay for expenditures, along the lines of Lucas (1982), Lucas and Stokey (1987), and Svensson (1985). Secondly, because holding cash reduces the effective tax rate by facilitating tax evasion. Demonetization in the model amounts to a forced conversion of cash into less liquid bank deposits, which in the presence of downward wage rigidity generates a decline in output, employment, and borrowing by firms. Households also switch to non-cash forms of payment to attenuate the impact of the cash shortage.

We then provide empirical evidence of the effects of demonetization. National time series aggregates alone cannot answer this question because they have limited coverage of the informal, cash-intensive sector of the economy, because the episode constitutes only a single observation, and because other economic shocks occurred during the period. Instead, we study the consequences of demonetization in the cross-section of Indian districts. Using a comprehensive data set from the RBI containing the geographic distribution of demonetized and new notes, we construct a local area demonetization shock as the ratio of 
post-demonetization to pre-demonetization currency in an area. We present both narrative and statistical evidence that these demonetization shocks occurred essentially at random with respect to local economic activity.

We study outcomes drawn from a number of different data sets, many of which have not previously been used in academic research. We first show that districts that experienced more severe demonetization shocks had much larger contractions in ATM withdrawals. The link between currency availability and cash withdrawals both validates the usefulness of our geographic shock measure and provides prima facie evidence of a cash shortfall.

We next show that demonetization had an adverse effect on real economic activity. Official data on economic activity at a subnational level and at high frequency do not exist. We use a new household survey of employment and satellite data on human-generated nightlight activity to measure demonetization's effects at the district level. Importantly, these variables capture both formal and informal sector economic activity. Both variables reveal economically sharp, statistically highly significant contractions in areas experiencing more severe demonetization shocks. The effects on real economic activity peak in the period immediately following the announcement and dissipate over the next few months as new currency arrives. In terms of magnitude, both variables map into a difference in output of roughly 4 percentage points between districts at the 10th and 90th percentile of the demonetization shock in the period immediately after the announcement. These results reject neutrality of money during demonetization.

Our third set of results demonstrate the adoption of alternative forms of payment technology in response to demonetization. While the difference in output across districts is substantial, it is far less than the roughly 50 percentage point inter-decile difference in the amount of currency replaced. In our model, this can occur if households endogenously found ways around using money to conduct transactions, for example by switching to alternative payment methods like debit cards, credit cards, and e-wallets or by convincing retailers to open an informal line of credit or to accept old notes. We use data on the transacted value of two leading electronic payments methods, e-wallet and point-of-service cards, to show that this substitution occurred. This pattern also corroborates our identifying assumption, as a confounding non-demonetization demand shock would instead induce positive comovement across all payments mechanisms and output.

Finally, experiencing more severe cash shortages had higher deposit growth as households could not withdraw money from their bank accounts. Credit growth in these areas nonetheless slowed, providing additional corroborating evidence of an effect on real activity. 
Our results imply that the decline in cash lowered the growth rate of economic activity by at least 2 p.p. in the quarter of demonetization. To reach this number, we first cumulate the cross-sectional effects on employment and nightlights over districts. Next, we argue that this calculation provides a lower bound for the aggregate consequences of the cash decline. Such a lower bound arises in our model due to cross-district trade. Combining these two results yields a decline in nightlights-based economic activity and of employment of 3 p.p. or more in November and December of 2016 relative to the counterfactual path, which translates into a decline in the quarterly growth rate of 2 p.p. or more. Similarly, the effect on credit implies a 2 p.p. or more decline in 2016Q4. ${ }^{1}$ We conclude that in modern India cash continues to serve an essential role in facilitating economic activity.

We review related literature next. Section 2 contains institutional details of demonetization. Section 3 presents the model and empirical predictions. Section 4 describes the data, the construction of the geographic demonetization shocks, and the conditions for causal interpretation of the analysis. Section 5 presents the cross-sectional results. Section 6 discusses the aggregate implications.

Related literature. A few early studies have used descriptive statistics (RBI, 2017b; Krishnan and Siegel, 2017) or simple time series methods (Aggarwal and Narayanan, 2017; Banerjee and Kala, 2017) to infer the effect of demonetization on the Indian economy. We introduce a number of new data sets and a cross-sectional empirical approach to more credibly identify the causal effects of the policy. Methodologically, this approach relates to a burgeoning literature using cross-sectional, regional variation to study macroeconomic topics, as reviewed in Nakamura and Steinsson (2018) and Chodorow-Reich (2019). This literature has so far avoided the topic of monetary policy because monetary policy is determined at the national (or higher) level. In contrast, our setting contains large cross-regional variation in the change in money. Ramey (2016) offers a forceful critique of time series studies of the effect of money on output as restricted to studying small changes in policy. Similar to Velde (2009) who traces the effects of large, overnight diminutions of coins in 18th century France, we study a sudden and very large decline in currency.

Our empirical results provide support for theoretical traditions which view money as essential in that the presence of money makes possible superior allocations. We follow Lucas (1982), Lucas and Stokey (1987), and Svensson (1985) in modeling the need for money through a cash-in-advance (CIA) constraint. The "new monetarist perspective" (Williamson

\footnotetext{
${ }^{1}$ These are non-annualized numbers.
} 
and Wright, 2010) instead introduces asymmetric information, limited commitment, and lack of double coincidence of wants to create a problem which money alleviates. ${ }^{2}$ Agrawal (2018) provides a model of a demonetization episode in this tradition. As noted by Kocherlakota (1998), any mechanism that creates a record of transactions ("memory") can substitute for money in a new monetarist economy. We document empirically one such substitution - the switch to e-wallet and POS payments technologies. Our model incorporates such substitution through an endogenous threshold for the CIA constraint, making it immune along this dimension to an otherwise clear example of the Lucas critique (Lucas, 1976) applying. ${ }^{3}$ In independent work, Crouzet, Gupta, and Mezzanotti (2019) also examine the adoption of alternative payment technology during demonetization and, like us, find persistent effects of demonetization on e-wallet use. Whereas their paper focuses on the network externalities of payment technologies, we emphasize the interplay between adoption of alternative means of payment and the effect on output.

Last, our paper sheds light on a debate around the possible benefits of a cashless economy. Rogoff (2016) articulates the societal costs of cash including putting a floor on the nominal interest rate and facilitating illegal activity and tax evasion. Nonetheless, he cautions that any phase-out of cash should take place slowly and with ample anticipation to allow households to adopt other forms of payment. Our results accord with these prescriptions.

\section{Demonetization}

On November 8, 2016, at 8:15pm local time, the Prime Minister of India announced in an unscheduled national televised address that the two largest denomination notes, the 500 $(\$ 7.5)$ and 1000 rupee $(\$ 15)$ notes, would cease to be legal tender, to be replaced by new 500 and 2000 notes. Effective at midnight, holders of the old notes could deposit them at banks but could not use them in transactions. The stated objectives of the policy were to target black money, reduce corruption, and remove fake currency notes (Modi, 2016). In the service of these objectives, the government placed deposit limits on customers who did not comply with "Know Your Customer" norms and set a deadline of December 31, 2016 for the return of old notes. ${ }^{4}$

\footnotetext{
${ }^{2}$ Lagos and Zhang (2018) argue theoretically that monetary models without money are generically poor approximations even to highly developed credit economies.

${ }^{3}$ Alvarez and Lippi (2009) examine the impact of financial innovation on the demand for cash.

${ }^{4}$ The December 31st limit applied to ordinary note holders. Non-resident Indian citizens could continue to deposit old notes until June 30, 2017. Customers who did not comply with the KYC norms could deposit a maximum of Rs 50,000. While all commercial banks and urban cooperative banks were allowed to accept
} 
Figure 1: Large Denomination Legal Tender

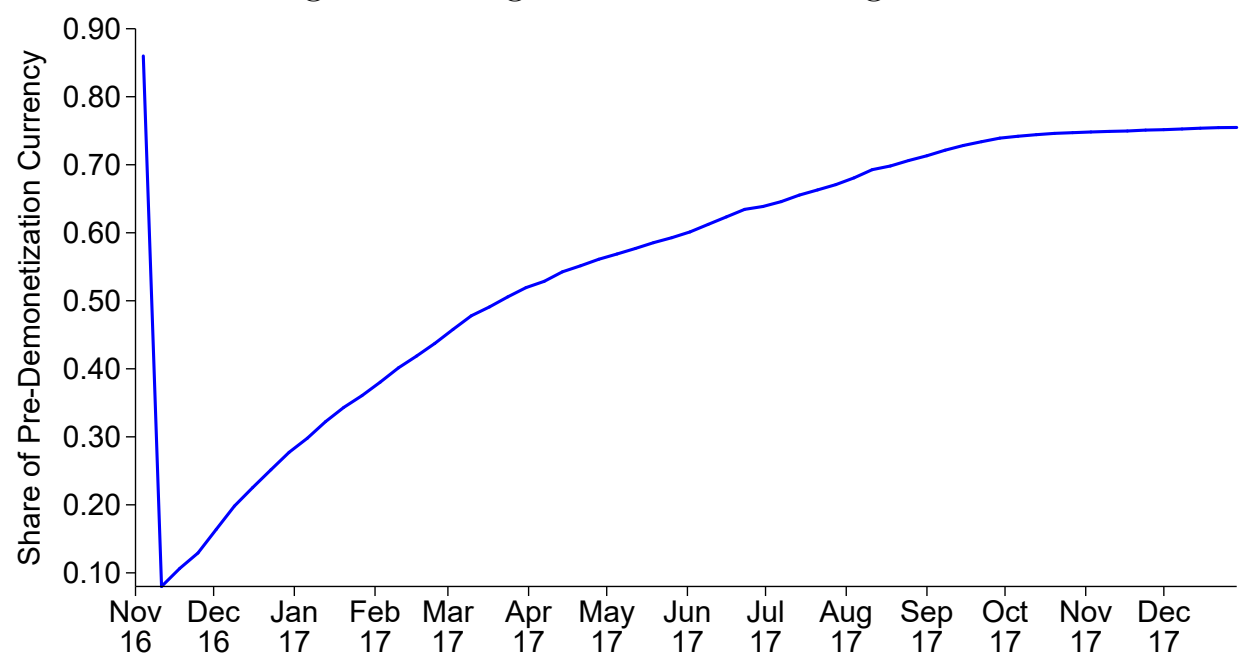

Notes: The figure plots the value of old 500 and 1000 notes (before November 8, 2016) and new 500 and 2000 notes (after November 8, 2016) as a share of total currency in circulation on November 4, 2016 using the currency chest data described below.

Figure 1 shows the path of large (500 rupee and above) legal tender denomination notes as a share of total pre-announcement currency outstanding, using the currency chest data described below. The old 500 and 1000 notes accounted for $86 \%$ of pre-demonetization currency. To maintain secrecy prior to the policy's announcement, the government and RBI did not print and distribute a large quantity of new notes before the announcement. Printing press constraints then prevented the government from quickly replacing more than a fraction of this total with new notes. Thus, total currency declined overnight by $75 \%$ and recovered only slowly over the next several months.

While the slow replacement of notes led to a decline in currency, it did not affect the overall size of the RBI's balance sheet or market interest rates. The immediate consequence was to increase deposits at commercial banks as households deposited old notes but could not freely withdraw new notes due to the cash shortage. ${ }^{5}$ The RBI initially required banks deposits in old currencies, district cooperative banks (DCCBs) were prohibited to do so.

${ }^{5}$ As we later show, the supply of new notes in a geographic area determined the total amount of withdrawals by households in that area. There were also legal limitations on withdrawals from individual accounts. The exchange of old for new notes was initially restricted to Rs 4000 (\$60) per person per day, cash withdrawals from bank accounts were initially limited to Rs. $10,000(\$ 150)$ per day and Rs 20,000 (\$300) per week, and withdrawals from ATM machines were initially restricted to Rs 2000 (\$30) per day per card (RBI, 2016). These limits were progressively relaxed and finally removed on January 30, 2017. The RBI carved out exceptions for special circumstances such as weddings. In addition, demonetized notes could be used to pay for certain transactions such as utility bills or to buy airline or train tickets. In total, there were 
Figure 2: RBI Liabilities

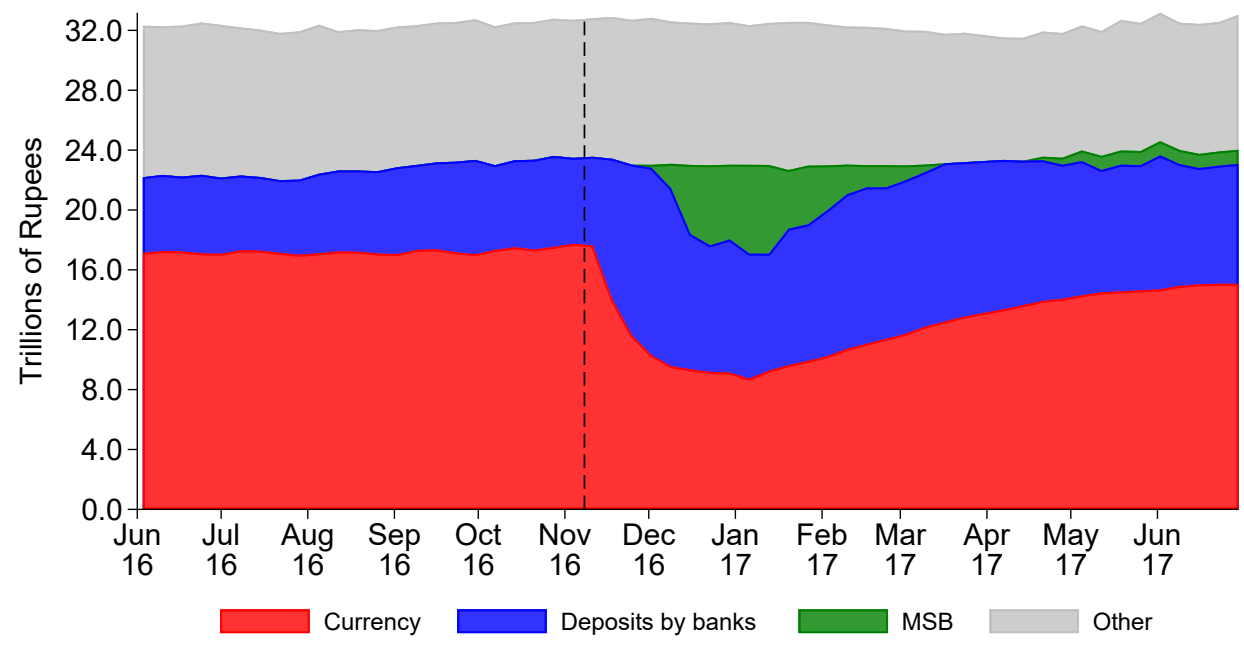

to hold these deposits as reserves at the RBI by increasing the cash reserve ratio to $100 \%$ on all incremental deposits received between September 16 and November 11. Since these reserves paid no interest while banks continued to pay positive interest on their deposits, on December 6 the RBI withdrew the increase in the reserve ratio and instead absorbed the deposits by issuing short-term Market Stabilization Bonds (MSB). ${ }^{6}$ Figure 2 shows the overall stability of RBI liabilities and the initial increase in commercial bank deposits, later replaced by MSB issuance. ${ }^{7}$ The stability of total liabilities also reflects the near total restoration of demonetized notes to the RBI, contrary to expectations early on that the inability to deposit black money might lead to the liquidation of a portion of the RBI's currency liabilities. ${ }^{8}$

21 separate press releases specifying rules changes issued by the RBI in November alone. Banerjee, Breza, Chandrasekhar, and Golub (2018) document general confusion about deposit and withdrawal limits caused by these many rules changes. Our focus in this paper concerns the total cash available for withdrawal and not how account limits affected the distribution of withdrawals across households.

${ }^{6} \mathrm{MSBs}$ are interest-paying government bonds sold by the RBI specifically to absorb liquidity and take the form of reverse-repo transactions. Technically, the RBI raised the ceiling on the quantity of MSB transactions it would conduct. In the peak months of demonetization (November and December 2016) the bonds took the form of 'cash management bills' with maturities of between 14 and 42 days.

${ }^{7}$ The currency liabilities shown in figure 2 decline more gradually than the sharp drop in legal tender shown in figure 1 . The difference occurs because demonetized notes remained liabilities of the RBI until they were exchanged for deposits or new notes or the time window to return them closed.

${ }^{8}$ According to RBI (2018), 99\% of total 500 and 1000 notes in circulation prior to demonetization were returned to the RBI. Moreover, the demonetized notes came back fairly quickly. Recall that most people had until December 31, 2016 to return their old notes. Using the currency chest data described below, we find that $69 \%$ of the notes were returned by the end of November; $87 \%$ of notes were returned by December 
Figure 3: Interest Rates Around Demonetization

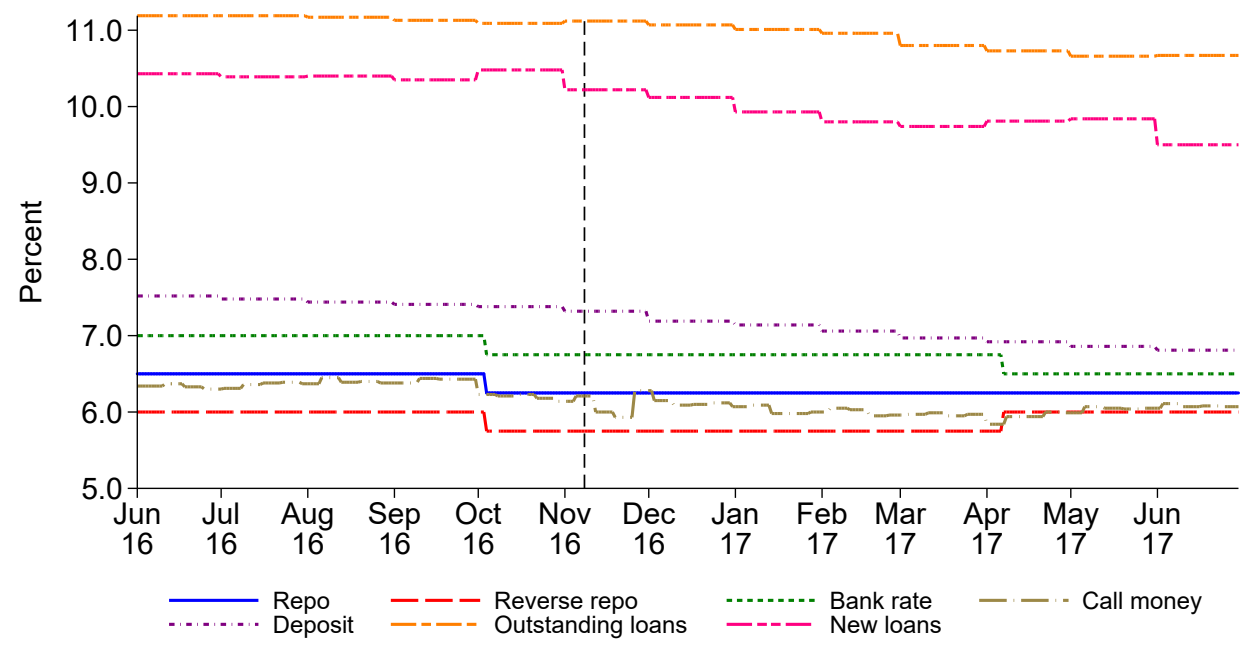

Thus, demonetization amounted to a conversion of household and business assets from cash into bank deposits and a corresponding exchange of currency for obligations to commercial banks on the liabilities side of the RBI's balance sheet.

Figure 3 plots a number of policy and market interest rates around demonetization. Not only did demonetization not coincide with any changes in the official policy rates (repo and reverse repo) used by the RBI, but private rates also changed little. Thus, the swap between two forms of RBI liabilities occurred without a corresponding change in market interest rates. Moreover, while households deposited their cash into banks, they could freely access these funds in the form of cheques, debit cards or credit cards. The only restriction was on spending using cash. This is the sense in which the Indian demonetization episode speaks directly to the specialness of cash.

\section{Model}

In this section we present a model of demonetization to generate testable cross-sectional implications and to bound the aggregate impact of demonetization. Unlike mainstream models, in our model an unanticipated fall in cash is not associated with a change in market interest rates, and we model the endogenous response of alternative forms of payment to 15 ; and $97 \%$ of notes were returned by the end of December. 
a cash shortage, both integral features of demonetization. The environment is a closed economy comprised of a continuum of identically sized regions indexed by $i$. The agents are households, firms, banks, and the government. Each region produces a non-traded good and a unique variety of a good $\omega$ which is traded freely across regions. We will consider both perfect labor mobility and perfectly immobile labor. An important friction is downward nominal wage rigidity owing to which equilibrium employment can fall short of inelastically supplied labor.

\subsection{Setup}

Households Households consume traded and non-traded goods. There are two stores of value, cash $M$ and interest earning deposits $D$. Households hold cash because of a cashin-advance (CIA) constraint along the lines of Lucas (1982), Lucas and Stokey (1987), and Svensson (1985) and because holding cash facilitates tax evasion and reduces the effective tax rate. Households in each region supply $\bar{N}$ units of labor inelastically. They choose consumption of tradeables $C_{i, t}^{T}$, consumption of nontradeables $C_{i, t}^{N}$, bank deposits $D_{i, t}$, cash holdings to carry into the next period $M_{i, t}$, and financial services $f_{i, t}$ to solve:

$$
\max _{C_{i, t}^{T}, C_{i, t}^{N}, D_{i, t}, M_{i, t}, f_{i, t}} \sum_{t=0}^{\infty} \beta^{t}\left[U\left(C_{i, t}\right)-h\left(f_{i, t}\right)\right]
$$

subject to,

$$
\begin{aligned}
P_{i, t} C_{i, t}+D_{i, t}+M_{i, t} & \leq R_{t-1} D_{i, t-1}+M_{i, t-1}+\left(1-\tau\left(\eta_{i, t}\right)\right) W_{i, t} N_{i, t}+T_{i, t}, \\
\kappa\left(f_{i, t}\right) P_{i, t} C_{i, t} & \leq M_{i, t-1}+T_{i, t}^{M} \\
C_{i, t} & =\left(C_{i, t}^{T}\right)^{\alpha}\left(C_{i, t}^{N}\right)^{1-\alpha}
\end{aligned}
$$

where all variables except for $C, f$, and labor $N$ are nominal and denominated in the unit of account (rupees). ${ }^{9}$ In the budget constraint (1), $\eta_{i, t}=\frac{M_{i, t}}{W_{i, t} N_{i, t}}$ is the ratio of cash balances accumulated in period $t$ to labor income, where $W_{i, t}$ denotes the wage, $\tau\left(\eta_{i, t}\right)$ is the effective labor income tax rate with $-1<\tau^{\prime}\left(\eta_{i, t}\right)<0$ so that the tax rate is decreasing in the ratio of cash holdings relative to labor income, and $T_{i, t}$ contains all transfers received from the government (cash and non-cash). Total consumption is an aggregate of traded and non-traded consumption, with the traded good itself an aggregate of varieties from differ-

\footnotetext{
${ }^{9}$ The objective function omits an expectations operator because we only consider a perfect foresight shock.
} 
ent regions: $C_{i, t}^{T}=\left(\int_{0}^{1} C_{i, t}^{T}(\omega)^{\frac{\sigma-1}{\sigma}} d \omega\right)^{\frac{\sigma}{\sigma-1}}$, where $\omega$ is the unique variety of tradable good produced in region $i$. The price aggregators are $P_{i, t}=\left(\alpha^{\alpha}(1-\alpha)^{1-\alpha}\right)^{-1}\left(P_{t}^{T}\right)^{\alpha}\left(P_{i, t}^{N}\right)^{1-\alpha}$, and $P_{t}^{T}=\left(\int_{0}^{1} P_{t}^{T}(\omega)^{1-\sigma} d \omega\right)^{\frac{1}{1-\sigma}}$

Equation (2) gives the CIA constraint wherein a fraction $0<\kappa\left(f_{i, t}\right) \leq 1$ of consumption spending requires a cash payment. This cash payment can be made using any money holdings brought into period $t$ from $t-1, M_{i, t-1}$, and cash transfers $T_{i, t}^{M}$ received from the government at time $t$. The cash share $\kappa$ depends on adoption of a finance technology $f_{i, t}$. This variable encompasses a broad range of actions that households can undertake when cash is scarce including switching to alternative payment methods like debit cards, credit cards, and ewallets and convincing retailers to open an informal line of credit or to accept old notes. Adopting the technology entails a utility cost (time and effort) $h\left(f_{i, t}\right)$. We assume $\kappa(0)=$ $\bar{\kappa}, \kappa^{\prime}\left(f_{i, t}\right) \leq 0, h(0)=0, h^{\prime}\left(f_{i, t}\right)>0, h^{\prime \prime}\left(f_{i, t}\right) \geq 0$. With these assumptions, households invest in the financing technology only when the CIA constraint binds. However, the CIA constraint does not necessarily bind when $R_{t}>1$ because of the tax advantage to holding cash.

Banks and Firms Perfectly competitive banks take deposits and lend to firms and to the government at interest rate $R_{t}$. Market clearing requires $\int_{i} A_{i, t}^{f} d i+A_{t}^{g}=\int_{i} D_{i, t} d i$, where $A_{i, t}^{f}$ is lending to firms and $A_{t}^{g}$ is lending to the government. Firms in both the tradable and nontradable sectors are perfectly competitive. Each firm faces a working capital constraint where a fraction $\varphi$ of the wage bill needs to be paid in advance. Firms take a loan $B_{i, t}^{f}=\varphi W_{i, t} N_{i, t}$ from the bank for this purpose. The production function for either good is $Y_{t}=N_{t}$. With perfect competition price equals marginal cost, $P_{t}^{T}(\omega)=P_{i, t}^{N}=\left(1+\varphi\left(R_{t}-1\right)\right) W_{i, t}$.

Downward Wage Rigidity As in Schmitt-Grohé and Uribe (2016), nominal wages are downwardly rigid: $W_{i, t} \geq \gamma W_{i, t-1}$. When the constraint does not bind $N_{i, t}=\bar{N}$, yielding the complementary slackness condition $\left(\bar{N}-N_{i, t}\right)\left(W_{i, t}-\gamma W_{i, t-1}\right)=0$ when labor is immobile across regions and $\left(\bar{N}-N_{t}\right)\left(W_{t}-\gamma W_{t-1}\right)=0$ when labor is mobile. Kaur (forthcoming) suggests $\gamma=1$ in India, in which case nominal wages never fall.

Government and Market Clearing The government prints (or destroys) money, $T_{i, t}^{M}=$ $M_{i, t}^{s}-M_{i, t-1}^{s}$, issues bonds $B_{i, t}^{g}$, collects labor income taxes, and makes transfers to households, yielding the consolidated budget constraint:

$$
\int_{0}^{1}\left(M_{i, t}^{s}+B_{i, t}^{g}+\tau\left(\eta_{i, t}\right) W_{i, t} N_{i, t}\right) d i=\int_{0}^{1}\left(T_{i, t}^{M}+T_{i, t}^{g}+M_{i, t-1}^{s}+R_{t-1} B_{i, t-1}^{g}\right) d i .
$$


Traded goods markets clear countrywide, $\int_{i} C_{i, t}^{T}(\omega) d i=Y_{t}^{T}(\omega)$. Non-traded goods markets clear by region, $C_{i, t}^{N}=Y_{i, t}^{N}$. Further, $A_{i, t}^{f}=B_{i, t}^{f}, A_{t}^{g}=B_{t}^{g}$, and $M_{i, t}^{s}=M_{i, t}$.

\subsection{Demonetization}

Appendix A characterizes a pre-demonetization steady state in which the CIA constraint does not bind due to the tax advantage of holding cash. At the start of period 0 the government (unexpectedly) announces that only a fraction of cash that households carry into period 0 is legal tender and can be used for transaction purposes and requires the remaining cash be deposited at the pre-fixed interest rate of $R_{-1}$. This policy forces households off their deposit Euler equation (A.3). At the start of period 1 demonetization ends and the money supply returns to the level required for full employment. There is no uncertainty following the announcement of the demonetization shock.

We first give an analytical solution for a uniform demonetization across all regions and when households do not have access to the finance technology, $\kappa^{\prime}(f)=0$. We assume a sufficiently sharp demonetization that the CIA constraint binds in period $0 .{ }^{10}$ Appendix A contains proofs of the propositions.

\section{Proposition 1 Uniform demonetization with constant $\kappa$}

Let $Z=M_{0}^{s} / M_{-1}^{s}=M_{0} / M_{-1}$ where $0<Z<1$ so that the $C I A$ binds and the wage constraint binds, that is $\bar{\kappa} P_{0} C_{0}=M_{0}$ and $W_{0}=\gamma W_{-1}$. If $Z$ is sufficiently low relative to the downward rigidity of wages, ${ }^{11} Z \cdot \frac{\eta_{-1}}{\bar{\kappa}\left(1+\varphi\left(\beta^{-1}-1\right)\right)}<\gamma$, then:

1. Output, employment decline: $\quad \frac{Y_{0}}{Y_{-1}}=\frac{N_{0}}{N_{-1}}=\frac{Z}{\gamma} \cdot \frac{\eta_{-1}}{\bar{\kappa}\left(1+\varphi\left(\beta^{-1}-1\right)\right)}$,

2. Bank lending to firms declines: $\frac{B_{0}^{f}}{P_{0}}=\frac{\varphi N_{0}}{\left(1+\varphi\left(R_{-1}-1\right)\right)}<\frac{B_{-1}^{f}}{P_{-1}}$,

3. Wages and prices satisfy:

$$
W_{0}=\gamma W_{-1}, P_{0}^{T}=P_{0}^{N}=\left(1+\varphi\left(\beta^{-1}-1\right)\right) \gamma W_{-1} .
$$

\footnotetext{
${ }^{10} \mathrm{As}$ long as the CIA binds we can solve for the outcomes in period 0 without the solutions for period 1 and beyond because interest rates are pre-fixed at $R_{-1}$ and the deposit Euler and money Euler equations are irrelevant. Verifying the conditions under which the CIA binds requires the full dynamic solution as shown in appendix A. Due to one-sided wage rigidity, multiple values of $M$ in period 1 induce a return to full employment. We choose the minimal such value, which requires an equilibrium wage $W_{1}>\gamma W_{0}=\gamma^{2} W_{-1}$ at which the downward wage rigidity is not binding. If $\gamma \approx 1$ then $M_{1} \approx M_{-1}$ and the cash to GDP ratio returns to the pre-demonetization level.

${ }^{11}$ The CIA does not bind in period -1 if $\frac{\eta_{-1}}{\bar{\kappa}\left(1+\varphi\left(\beta^{-1}-1\right)\right)}>1$ (see appendix A). Therefore, $Z / \gamma$ must be sufficiently less than 1 . The condition does not depend only on $Z / \gamma$ because the nominal wage when the CIA binds is different from when the CIA does not bind.
} 
The proportional decline between output and $Z$ in equation (4) arises because of the binding CIA constraint $M_{0}=\bar{\kappa} P_{0} C_{0}$, which tightly links cash in period 0 to output $Y_{0}=C_{0} \cdot{ }^{12}$ The ratio of money holdings to labor income falls, $\eta_{0}<\eta_{-1}$, owing to which the effective tax rate rises, $\tau_{0}>\tau_{-1}$, but this is not distortionary because of perfectly inelastic labor supply. The shadow interest rate, which is the interest rate consistent with the deposit Euler equation, rises: $R_{0}^{s} \equiv \frac{\lambda_{0}}{\beta \lambda_{1}}=\frac{1}{\left(1-\nu \tau\left(\eta_{0}\right)\right)}>\frac{1}{\left(1-\nu \tau\left(\eta_{-1}\right)\right)}=R_{-1}$.

We next consider the case where the decline in $M$ is not uniform across regions, as we exploit in our empirical work. The government reduces the supply of cash in region $i$ in a proportion $Z_{i} \in(0,1)$, i.e. $M_{i, 0}^{s}=Z_{i} M_{-1}^{s}$. We assume households cannot undo the heterogeneous distribution of cash across regions through financial markets.

\section{Proposition 2 Non-uniform demonetization with constant $\kappa$}

If the drop in each region is sufficient to make the CIA constraint and wage constraint bind in all regions, that is, $\bar{\kappa} P_{i, 0} C_{i, 0}=M_{i, 0}$ and $W_{i, 0}=\gamma W_{-1} \forall i$, then:

1. Regions with higher $Z_{i}$ have smaller declines in output:

$$
\frac{Y_{i, 0}}{Y_{i,-1}}=\frac{Y_{0}^{T}(\omega)+Y_{i, 0}^{N}}{Y_{i,-1}}=\frac{\alpha Z+(1-\alpha) Z_{i}}{\gamma} \cdot \frac{\eta_{-1}}{\bar{\kappa}\left(1+\varphi\left(\beta^{-1}-1\right)\right)},
$$

2. Firm borrowing falls less in regions with higher $Z_{i}$ :

$$
\frac{B_{i, 0}^{f}}{P_{0}}=\frac{\varphi Y_{i 0}}{\left(1+\varphi\left(\beta^{-1}-1\right)\right)}
$$

3. Wages and prices satisfy: $\quad W_{i, 0}=\gamma W_{-1}, P_{0}^{T}=P_{i, 0}^{N}=\left(1+\varphi\left(\beta^{-1}-1\right)\right) \gamma W_{-1}$.

The impact of the idiosyncratic component of the money shock is decreasing in the size of the traded sector; as $\alpha \rightarrow 1$ there is no cross-regional variation in output. Regional employment tracks regional output. Because of downward wage rigidity, the wage is equalized across regions regardless of labor mobility. Firm borrowing is increasing in $Z_{i}$. If all banks operate nationally then there is no necessary relation between local firm borrowing and loans extended by local banks. If however banks or firms face a (vanishingly) small cost to forming a cross-region lending relationship and banks have perfect internal credit markets, then there is a greater decline in credit creation by bank branches located in a region with a smaller $Z_{i}$.

\footnotetext{
${ }^{12}$ Starting from the binding CIA constraint $M_{0}=\bar{\kappa} P_{0} C_{0}$, we substitute the equilibrium conditions $P_{0}=$ $\left(1+\varphi\left(R_{-1}-1\right)\right) W_{0}=\left(1+\varphi\left(\beta^{-1}-1\right)\right) \gamma W_{-1}$ and $Y_{t}=C_{t}=N_{t}$ and the definitions $\eta_{-1}=\frac{M_{-1}}{W_{-1} N_{-1}}$ and $Z=\frac{M_{0}}{M_{-1}}$ to arrive at equation (4). As is clear, while in our setup $P_{0}$ is sticky downwards because of the downward wage rigidity, any nominal friction that keeps $P_{0}$ from falling will result in a similar expression.
} 


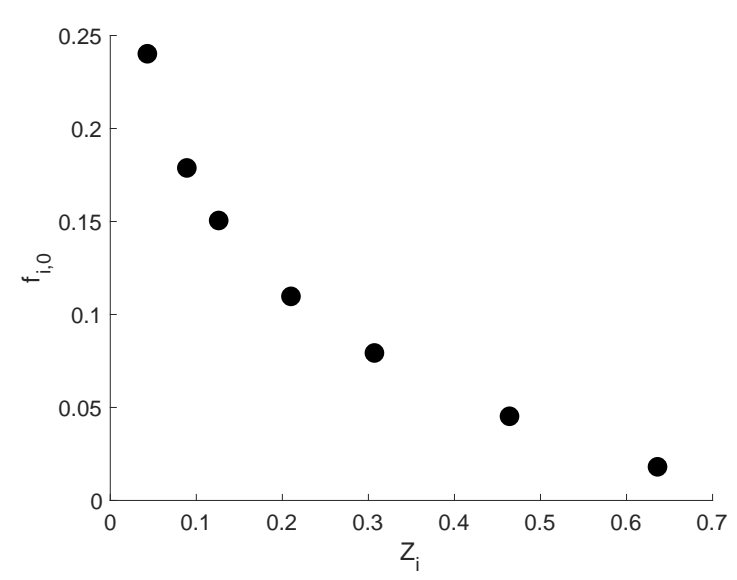

(a) Financial Services

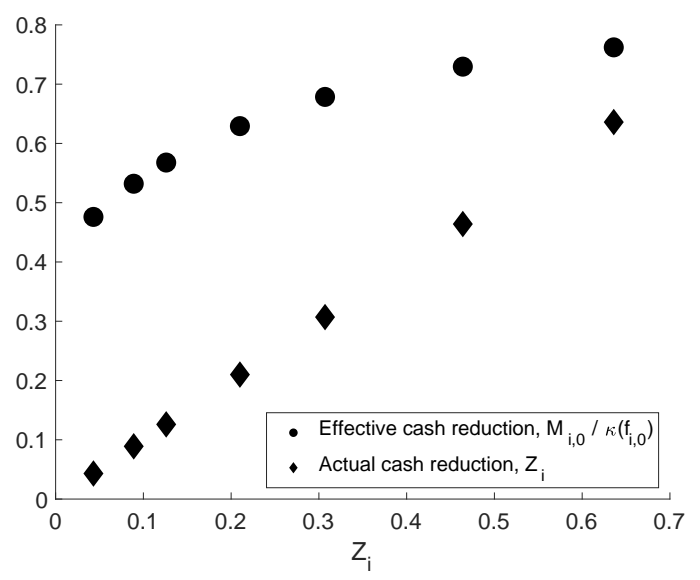

(b) Effective Cash Shortage

Figure 4: Adoption of non-cash forms of payment

Finally, we allow for endogenous $\kappa$. The endogenous $\kappa$ breaks the unit elasticity between $M$ and output in equation (4). In the absence of a closed form solution, we provide a numerical illustration of how $f_{i, 0}$ varies with $Z_{i}{ }^{13}$ Figure 4 (a) shows that regions with a larger drop in cash adopt more financial services. Financial services make the effective cash shortage $Z_{i} / \kappa_{i, 0}$ smaller than the measured cash shortage $Z_{i}$ and, because of the selection effect, there is less heterogeneity in the effective cash shortage across regions, as depicted in figure 4(b). Overall, the cross-sectional relationship between cash and output is attenuated.

To summarize, the model predicts that districts experiencing more severe demonetization will have: (i) relative reductions in employment and output; (ii) faster adoption of alternative payment technologies; and (iii) lower bank credit growth. In addition, trade linkages make cross-sectional estimates a lower bound for aggregate effects.

\footnotetext{
${ }^{13}$ The full solution requires solving for the Lagrange multiplier on the CIA constraint $\theta_{i, 0}$, financing technology $f_{i, 0}$, and the cash share $\eta_{i, 0}$ using the three equations: $\theta_{i, 0}=\frac{1}{Z_{i} M_{-1}}-\frac{1}{\kappa\left(f_{i, 0}\right)} \frac{\beta \lambda_{i, 1}}{1+\tau^{\prime}\left(\eta_{i, 0}\right)}, \eta_{i, 0}=$ $\frac{Z_{i}\left(1+\varphi\left(\beta^{-1}-1\right)\right)}{\alpha \mathcal{I}+(1-\alpha) \frac{Z_{i}}{\kappa\left(f_{i, 0}\right)}}, \theta_{i, 0} Z_{i} M_{-1}=-\frac{h^{\prime}\left(f_{i, 0}\right) \kappa\left(f_{i, 0}\right)}{\kappa^{\prime}\left(f_{i, 0}\right)}$, where $\lambda_{i, 1}=\frac{\eta_{-1}}{M_{1}(1+\varphi(1 / \beta-1))}$ and $\mathcal{I}=\int \frac{Z_{j}}{\kappa\left(f_{j, 0}\right)} d j$. See Appendix A for details.
} 
Table 1: Data Sets

\begin{tabular}{lll}
\hline \hline Name & Source & Coverage \\
\hline Currency chests & RBI & $\begin{array}{l}\text { Daily cash flow accounting statements by note de- } \\
\text { nomination for all currency chests in India aggre- } \\
\text { gated to district level }\end{array}$ \\
\hline Consumer Pyramids & $\begin{array}{l}\text { Centre for Monitoring the Indian } \\
\text { Economy (CMIE) }\end{array}$ & $\begin{array}{l}\text { Monthly household survey containing employment } \\
\text { status of about 110,000 adults in sample }\end{array}$ \\
\hline Nightlights & VIIRS DNB & $\begin{array}{l}\text { Low-light imaging data collected by satellite and } \\
\text { filtered to measure the quantity of artificial (i.e. } \\
\text { human-generated) light in an area }\end{array}$ \\
\hline ATM transactions & $\begin{array}{l}\text { National Payments Corporation } \\
\text { of India (NPCI) }\end{array}$ & $\begin{array}{l}\text { Monthly value of all ATM withdrawals covered by } \\
\text { NPCI aggregated to district level }\end{array}$ \\
\hline POS transactions & National Payments Corporation \\
of India (NPCI) & $\begin{array}{l}\text { Monthly value of all point-of-sale (POS) transac- } \\
\text { tions covered by NPCI aggregated to district level }\end{array}$ \\
\hline e-Wallet transactions & Wallet company & $\begin{array}{l}\text { Monthly index of value of e-wallet transactions ag- } \\
\text { gregated to district level }\end{array}$ \\
\hline Bank deposits & RBI & $\begin{array}{l}\text { End-of-quarter deposits at all bank branches in } \\
\text { each district }\end{array}$ \\
\hline Bank credit & RBI & $\begin{array}{l}\text { End-of-quarter credit outstanding from all bank } \\
\text { branches in each district }\end{array}$ \\
\hline District GDP & Indicus & $\begin{array}{l}\text { Annual district GDP per capita and sectoral GDP } \\
\text { shares through 2015 }\end{array}$ \\
\hline \hline
\end{tabular}

\section{Data and Summary Statistics}

\subsection{Data}

We merge several data sets, many of which have not previously been used in academic research. The variety of data sets allow us to report both financial and real outcomes including coverage of the informal sector. Our main geographic level of aggregation is the district. India contains approximately 600 districts which partition the country. Table 1 summarizes the data sets used.

Currency shocks. We construct geographic demonetization shocks using currency chest records maintained by the RBI. A currency chest functions as a warehouse of currency notes for the RBI but is physically located in and administered by a commercial bank. There are approximately 4000 chests spread across the country. A chest may receive newly printed 
Table 2: Example Currency Chest

\begin{tabular}{|c|c|c|c|c|c|c|c|c|c|}
\hline \multirow[t]{2}{*}{ Date } & \multirow[t]{2}{*}{ Note } & \multirow[b]{2}{*}{ Open } & \multicolumn{3}{|c|}{ Inflows } & \multicolumn{3}{|c|}{ Outflows } & \multirow[b]{2}{*}{ Close } \\
\hline & & & Remit & $D I$ & Dep & Soiled & DO & Wit & \\
\hline $11 / 15 / 2016$ & 2000 & 100 & 50 & 20 & 0 & 0 & 10 & 80 & 80 \\
\hline $11 / 15 / 2016$ & 1000 & 800 & 0 & 0 & 200 & 600 & 0 & 0 & 400 \\
\hline $11 / 15 / 2016$ & 500 & 400 & 10 & 0 & 20 & 100 & 0 & 10 & 320 \\
\hline
\end{tabular}

notes either directly from one of the 19 RBI issue offices or from one of approximately 600 "hub" chests. Each chest in turn sends currency to and receives currency from individual commercial banks located in its geographic vicinity. Thus, all newly printed notes available for withdrawal from a commercial bank first pass through the correspondent currency chest.

Our data consist of daily cash flow accounting statements reported by each currency chest, separately by note denomination. Table 2 provides an example for a hypothetical chest after demonetization has occurred. The statements report the opening quantity of notes at the chest (Open), new notes remitted directly by an RBI office (Remittances), notes received from other chests $(D I)$, deposits of notes by commercial banks $(D e p)$, soiled notes sent back to an RBI office for destruction (Soiled), notes sent to other chests $(D O)$, withdrawals of notes by commercial banks (Wit), and the closing quantity of notes at the chest (Close). We additionally define $N D=D I-D O$ as net diversions of currency received from other chests. We aggregate the chest-level data to the district level.

We define the demonetization shock in district $i$ at date $t$ post-demonetization, $Z_{i, t}$, as the value of non-demonetized currency in the district as of date $t$ divided by the total value of currency in the district before demonetization. Letting $M_{i, t}^{n e w}$ denote the value of all new notes received in district $i$ as of date $t$ post-demonetization, $M_{i}^{1000}$ and $M_{i}^{500, \text { old }}$ the value of demonetized 1000 and 500 notes, respectively, from district $i$ (i.e. the value of notes in chests or in circulation as of November 8$)$, and $M_{i}^{\text {small }}$ the pre-demonetization value of small notes, we can express $Z_{i, t}$ as:

$$
Z_{i, t}=\frac{M_{i, t}^{\text {new }}+M_{i}^{\text {small }}}{M_{i}^{1000}+M_{i}^{500, \text { old }}+M_{i}^{\text {small }}}
$$

We operationalize equation (10) by constructing the following variables from the currency 
chest data:

New 2000 notes: $\quad M_{i, t}^{2000}=\sum_{s=\text { Oct } 26,2016}^{t}\left(\right.$ Remit $\left._{i, s}^{2000}+N D_{i, s}^{2000}\right)$,

New 500 notes: $\quad M_{i, t}^{500, \text { new }}=\sum_{s=\text { Nov } 9,2016}^{t}\left(\right.$ Remit $\left._{i, s}^{500}+N D_{i, s}^{500}\right)$,

New small notes: $\quad M_{i, t}^{\text {small,new }}=\sum_{s=\text { Nov } 9,2016}^{t}\left(\right.$ Remit $\left._{i, s}^{\text {small }}+N D_{i, s}^{\text {small }}\right)$,

All new notes: $\quad M_{i, t}^{\text {new }}=M_{i, t}^{2000}+M_{i, t}^{500, \text { new }}+M_{i, t}^{\text {small,new }}$,

Demon. 1000 notes: $\quad M_{i}^{1000}=\sum_{s=\operatorname{Nov} 9,2016}$ Soiled $_{i, s}^{1000}+$ Close $_{i, \mathrm{Jan} 31,2016}^{1000}$

Demon. 500 notes: $\quad M_{i}^{500, \text { old }}=\sum_{s=\text { Nov } 9,2016}$ Soiled $_{i, s}^{500}$,

Pre-demon. small notes: $\quad M_{i}^{\text {small }}=\left(\frac{\sum_{s=\text { Jan 1, 2014 }}^{\text {Dec 31 2015 }}\left(D e p_{i, s}^{\text {small }}+W i t_{i, s}^{\text {small }}\right)}{\sum_{s=\text { Jan } 1,2014}^{\text {Dec } 31,2015}\left(D e p_{i, s}^{500}+W i t_{i, s}^{500}\right)}\right) M_{i}^{500, \text { old }}$.

Equation (11) states that we measure new 2000 notes by summing notes received directly from RBI offices and net notes received from other chests. ${ }^{14}$ We measure new 500 notes, $M_{i, t}^{500, \text { new }}$, analogously, as well as smaller denomination (100, 50, 20, 10, and 5) notes, $M_{i, t}^{\text {small,new }}$, printed by the RBI to help meet currency demand. We measure demonetized 1000 notes, $M_{i}^{1000}$, as the sum from the day after demonetization to the last day in our data set, January 31, 2018, of the value of 1000 notes returned to RBI offices plus any 1000 notes remaining in a chest as of that date, and demonetized 500 notes, $M_{i}^{500, o l d}$, by summing the value of 500 notes returned to RBI offices. ${ }^{15}$ Finally, we do not directly observe the

\footnotetext{
${ }^{14}$ This measure spikes temporarily when a chest receives notes from an RBI issue office which it subsequently sends to other chests. To remove these spikes, we additionally apply a lower-envelope operator to $M_{i, t}^{2000}$ which takes the minimum value of new notes over periods $t$ forward. That is, our actual measure modifies equation (11) to be $M_{i, t}^{2000}=\min _{t^{\prime} \geq t} \sum_{p=\text { Oct } 26,2016}^{t^{\prime}}\left(\operatorname{Remit}_{i, p}^{2000}+N D_{i, p}^{2000}\right)$. We do not apply this operator to 500 notes as defined in equation (12) because the data do not distinguish between net diversions of new and demonetized 500 notes. Our results are quantitatively robust to not applying this operator to the 2000 notes.

${ }^{15}$ We cannot include the January 31,2018 balance of old 500 notes in the measure of $M_{i}^{500, \text { old }}$ because the data do not distinguish between balances of old and new 500 notes. Likewise, soiled 500 notes returned after demonetization may contain some new 500 notes, explaining why we truncate the summation at the end of December 2017. While these factors imply $M_{i}^{500, \text { old }}$ is measured with error, we believe such measurement
} 
stock of small notes before demonetization. Instead, we make the assumption that, predemonetization, all notes of denomination 500 and below flow through currency chests at the same rate, and use the relative gross flows (withdrawals and deposits) and the stock of 500 notes to construct $M_{i}^{\text {small }}$ as shown in equation (17). Under this assumption, the crossdistrict mean large note share equals $89 \%$, very close to the pre-demonetization national share of the stock of large notes as reported by the RBI. ${ }^{16}$

We apply a few filters to remove districts with implausible demonetization shocks: we drop observations with $Z_{i, t}<0, M_{i}^{500, \text { old }} \leq 0$, or where $\sum_{p=\text { Nov } 9,2016}^{t}\left(W i t_{i, p}^{2000}-D e p_{i, p}^{2000}\right)<$ 0 or differs from $M_{i, t}^{2000}$ by more than a factor of 3 . That is, we require that new currency arriving in a district be non-negative, that we observe a positive quantity of old 500 notes, that cumulative deposits of 2000 notes by commercial banks not exceed cumulative withdrawals, and that cumulative withdrawals net of deposits (i.e. net new 2000 notes actually received by commercial banks) not differ from arrivals of new 2000 notes by too much. ${ }^{17}$ Applying these criteria removes 47 of 589 districts which collectively contain less than $3 \%$ of demonetized currency.

Employment. We obtain data on employment status from Consumer Pyramids starting in January 2016. Unlike countries such as the United States, India does not have a governmental monthly household survey or a monthly survey of establishments. ${ }^{18}$ The Centre for Monitoring the Indian Economy, a private organization, conducts a nationally representative household survey referred to as Consumer Pyramids, which includes questions on employment status similar to those asked in the Current Population Survey (CPS) in the United States. Specifically, an individual counts as employed if on the day of the survey or the

error is small. Moreover, the vast majority of cross-sectional variation in currency replacement comes from 1000 and 2000 notes, not 500 notes. A regression of $\ln Z_{i, t}$ on $\ln \left(M_{i, t}^{2000} / M_{i}^{1000}\right)$ for $t=$ December 2016 yields an $R^{2}$ of 0.84 . Adding $\ln \left(M_{i, t}^{500, \text { new }} / M_{i, t}^{500, \text { old }}\right)$ to the regression raises the $R^{2}$ only slightly to 0.88 .

${ }^{16}$ We use the currency flow rate of 500 notes because of the possibility that some 1000 notes were used for storage and therefore did not flow through chests at the same rate as other notes. Nonetheless, using the average flow of 500 and 1000 notes yields an alternative $Z_{i, t}$ which has a correlation of 0.999 with the measure defined in the text. Yet another alternative assumes all districts have the same share of large notes of 0.87 as reported by the RBI for the national economy. Table B.2 in the online appendix reproduces our main results using this alternative measure and shows our main findings remain unchanged.

${ }^{17}$ Cumulative withdrawals net of deposits may differ from new arrivals of notes because currency withdrawn by a commercial bank in one district may go to a customer who re-deposits the notes in a bank in a different district. However, large discrepancies between the measures are rare and signal some restriction on withdrawals which we do not observe.

${ }^{18}$ In April 2018 the Central Statistics Office began reporting monthly employment counts for formal sector firms based on administrative tax records, with data back to September 2017. The non-coverage of the demonetization period or of informal sector employment make these data inappropriate for our analysis. 
day prior, the individual (i) did any paid work, (ii) was on paid or unpaid leave, (iii) was not working because his/her workplace was temporarily shut down for maintenance or labor dispute but expected to resume work within 15 days, (iv) owned a business in operation, or (v) assisted in a family business. The survey covers roughly 110,000 adults (persons 15+) per month, comparable to the sample size (although not the coverage rate) of the CPS. ${ }^{19}$

We construct district-month measures of employment and population by aggregating the individual observations using the survey weights. This step introduces four complications. First, while the survey has national representation, it does not field in every district in every month. Rather, it uses a rotation schedule wherein each primary sampling unit (a town or village) with households in the sample gets visited once every four months. This pattern means that most districts appear in the sample only once every four months, with larger districts surveyed more frequently. The typical month therefore contains observations drawn from roughly 150 districts. For this reason, we pool over adjoining months to increase the sample size. Second, the survey is in the field continuously over the course of a month and we do not know the exact interview date for each respondent. We exclude November 2016 from the analysis since responses in that month mix pre-demonetization and post-demonetization outcomes. Third, the survey weights do not aggregate to estimates of district population that are consistent across months. We therefore use the ratio of total employed to persons 15 and older as our main outcome. Finally, we weight regressions using this variable by the number of individual-level observations in the district to reflect the aggregation step.

Nightlights. Our second measure of real activity following demonetization is the change in nightlight intensity. Nightlight intensity refers to low-light imaging data collected by satellite and filtered to measure the quantity of artificial (i.e. human-generated) light in an area. Such data have been used to augment official measures of output and output growth and to generate estimates for areas or periods where official data are unavailable (Henderson, Storeygard, and Weil, 2012). In our context, nightlight intensity could reflect shops closing early because of a lack of customers or lower activity in factories which usually operate after dark.

We use the VIIRS DNB data collected by NOAA using the Suomi National Polar Partnership satellite, which was launched in 2011 (Elvidge, Baugh, Zhizhin, Hsu, and Ghosh,

\footnotetext{
${ }^{19}$ The survey shares other similarities with the CPS and the Survey of Income and Program Participation (SIPP), such as the use of a stratefied sampling design (based on the 2011 Census) and a rotation structure wherein individual sampling units enter the survey every four months. The survey does not include any units from the following states or union territories: Arunachal Pradesh, Nagaland, Manipur, Mizoram, Tripura, Meghalaya, Sikkim, Andaman \& Nicobar Islands, Dadra \& Nagar Haveli, Lakshadweep and Daman and Diu.
} 
2017). Despite the filtering, some stray light remain in these data. NOAA provide annual composites which contain additional processing to remove such stray light. We follow World Bank (2017) in removing cells (roughly $0.5 \mathrm{~km}^{2}$ ) for which the annual average of the data differ substantially from the annual composites and then aggregating to the district level. The resulting data are monthly frequency and contain substantial seasonality. We seasonally adjust the data in both levels and logs by regressing nightlights on district-specific linear time trends and month categorical variables over the period April 2012 to March 2016, remove the month-specific factors, and then keep the series for each district (unadjusted, adjusted in levels, adjusted in logs) with the smallest variance. This procedure uses only data from before demonetization to perform the seasonal adjustment. Finally, we aggregate the monthly data to quarterly to remove very high frequency volatility, dropping October 2016 from 2016Q4 so that 2016Q4 is (almost entirely) post-demonetization.

ATM/POS. We obtain monthly data for the period January 2016 to June 2017 on the value of ATM withdrawals and point-of-sale (POS) transactions by PIN code from National Payments Corporation of India (NPCI), an umbrella organization set up by the RBI to operate retail payments systems. A POS terminal is a device which enables payment by credit or debit card over a telephone line or internet connection. We aggregate the data to the district level using a concordance file from the post office. Where a PIN code covers multiple districts, we assign the district based on the location of the main post office in the district.

E-Wallet. We obtain monthly indexes of the total value of e-wallet transactions by district from a wallet company for the period September 2016 to July 2017. E-Wallet technology functions similar to pre-paid cards. ${ }^{20}$

Bank deposits and credit. We obtain publicly available end-of-quarter data on bank deposits and credit outstanding by district from the RBI Quarterly Statistics on Deposits and Credit of Scheduled Commercial Banks. These data come from branch-level reporting. Therefore, district-level deposits correspond to deposits in accounts opened at branches within the district. Likewise, district-level credit means loans granted by loan officers at branches within the district regardless of the location of the borrower.

\footnotetext{
${ }^{20}$ The wallet company issued the following disclaimer: "Wallet company shared only normalized data on payments to merchants at an aggregate level for academic research. No user data has been shared in any form. Wallet company does not have any role in drawing inferences of the study and the views expressed in the study are solely of the authors."
} 
GDP and population. We obtain district-level measures of GDP, sectoral GDP, and population from Indicus, a private data firm, and use these data to convert various series to a per capita basis and as control variables below. For all three variables we use data from 2015, the last year of data available. We obtain national quarterly seasonally-adjusted nominal and real GDP from OECD. ${ }^{21}$

\subsection{Summary Statistics}

Table 3 reports cross-district summary statistics for December 2016, March 2017, and June 2017. The median district in December 2016 had currency equal to $42 \%$ of its predemonetization level. Essentially all districts experienced a contraction, with the 90th percentile district at $70 \%$ of its pre-demonetization level. At the other extreme, the 10th percentile district had currency equal to only $33 \%$ of its pre-demonetization level. By March 2017, currency in the median district had recovered to $83 \%$ of its pre-demonetization level and by June 2017 the median district had no net contraction remaining. Thus, in the first few months demonetization affected essentially all areas of India but with varying intensity, and by summer 2017 the shock had mostly been undone.

\subsection{What Determines Geographic Variation in the Shock?}

The next section reports cross-sectional correlations of outcome measures with the demonetization shock. Causal interpretation of these correlations requires that the variation in demonetization intensity be uncorrelated with the no-demonetization baseline paths of the outcome variables, similar to the parallel trends assumption required in difference-in-difference estimation.

As a starting point, the demonetization shock $Z_{i, t}$ could vary across districts because of variation in the pre-demonetization share of large notes or because of variation in the arrival rate of new notes. In fact, table 3 shows that the pre-demonetization share of large notes varies little across districts, with a standard deviation of $s_{i}$ of 4 percentage points and an interdecile range of $83 \%$ to $95 \%$. As a result, essentially all of the variation in $Z_{i, t}$ comes from variation in the replacement rate of demonetized notes; the correlation of $Z_{i, t}$ and an alternative measure that sets the large note share to the national level of 0.87 reported by the RBI is above 0.99 .

\footnotetext{
${ }^{21}$ The Indian Ministry of Statistics does not publish a seasonally-adjusted measure of quarterly GDP.
} 
Table 3: Summary Statistics

\begin{tabular}{|c|c|c|c|c|c|c|}
\hline & Mean & SD & P10 & $\mathrm{P} 50$ & P90 & Count \\
\hline \multicolumn{7}{|l|}{ December 2016} \\
\hline Demonetization shock & 0.45 & 0.23 & 0.22 & 0.42 & 0.70 & 542 \\
\hline Pre-demon. large note share & 0.89 & 0.04 & 0.83 & 0.89 & 0.95 & 542 \\
\hline Nightlights (log change) & -0.08 & 0.22 & -0.33 & -0.08 & 0.16 & 541 \\
\hline ATM transactions (log change) & -0.85 & 0.42 & -1.44 & -0.77 & -0.42 & 535 \\
\hline POS transactions (log change) & 2.26 & 0.83 & 1.35 & 2.19 & 3.31 & 526 \\
\hline E-Wallet transactions (log change) & 0.68 & 0.34 & 0.34 & 0.65 & 1.07 & 516 \\
\hline Bank deposits (log change) & 0.12 & 0.05 & 0.06 & 0.12 & 0.19 & 535 \\
\hline Bank credit (log change) & -0.01 & 0.04 & -0.04 & -0.01 & 0.02 & 535 \\
\hline 2015 GDP per capita (Mi) & 0.10 & 0.08 & 0.04 & 0.09 & 0.18 & 540 \\
\hline 2015 Agriculture share of GDP & 0.16 & 0.12 & 0.03 & 0.14 & 0.34 & 532 \\
\hline Population per sq. km (Th) & 1.24 & 8.70 & 0.16 & 0.47 & 1.45 & 539 \\
\hline \multicolumn{7}{|l|}{ March 2017} \\
\hline Demonetization shock & 0.90 & 0.42 & 0.48 & 0.83 & 1.36 & 550 \\
\hline Pre-demon. large note share & 0.89 & 0.04 & 0.83 & 0.89 & 0.95 & 550 \\
\hline Nightlights (log change) & 0.18 & 0.26 & -0.09 & 0.15 & 0.49 & 548 \\
\hline ATM transactions (log change) & 0.01 & 0.31 & -0.19 & 0.01 & 0.24 & 544 \\
\hline POS transactions (log change) & 1.73 & 0.95 & 0.87 & 1.66 & 2.76 & 531 \\
\hline E-Wallet transactions (log change) & 0.91 & 0.30 & 0.54 & 0.90 & 1.28 & 520 \\
\hline Bank deposits (log change) & 0.13 & 0.06 & 0.07 & 0.12 & 0.19 & 543 \\
\hline Bank credit (log change) & 0.06 & 0.05 & 0.02 & 0.07 & 0.11 & 543 \\
\hline \multicolumn{7}{|l|}{ June 2017} \\
\hline Demonetization shock & 1.23 & 0.60 & 0.61 & 1.11 & 1.95 & 548 \\
\hline Pre-demon. large note share & 0.89 & 0.04 & 0.83 & 0.89 & 0.95 & 548 \\
\hline Nightlights (log change) & 0.28 & 0.31 & -0.02 & 0.26 & 0.67 & 546 \\
\hline ATM transactions (log change) & -0.03 & 0.21 & -0.18 & -0.04 & 0.16 & 542 \\
\hline POS transactions (log change) & 1.77 & 0.80 & 0.98 & 1.69 & 2.66 & 530 \\
\hline E-Wallet transactions (log change) & 1.14 & 0.35 & 0.73 & 1.16 & 1.53 & 518 \\
\hline Bank deposits (log change) & 0.12 & 0.05 & 0.07 & 0.12 & 0.18 & 541 \\
\hline Bank credit (log change) & 0.08 & 0.06 & 0.02 & 0.08 & 0.12 & 541 \\
\hline
\end{tabular}

Figure 5 shows a map of the demonetization shock in December 2016 by district, with districts with larger shocks shaded darker. The RBI offices in some states appear to have received more new currency notes than in others. We address the spatial correlation in what follows by clustering standard errors by state.

A violation of parallel trends could occur if the RBI steered new notes toward areas with 
Figure 5: Demonetization Shock by District

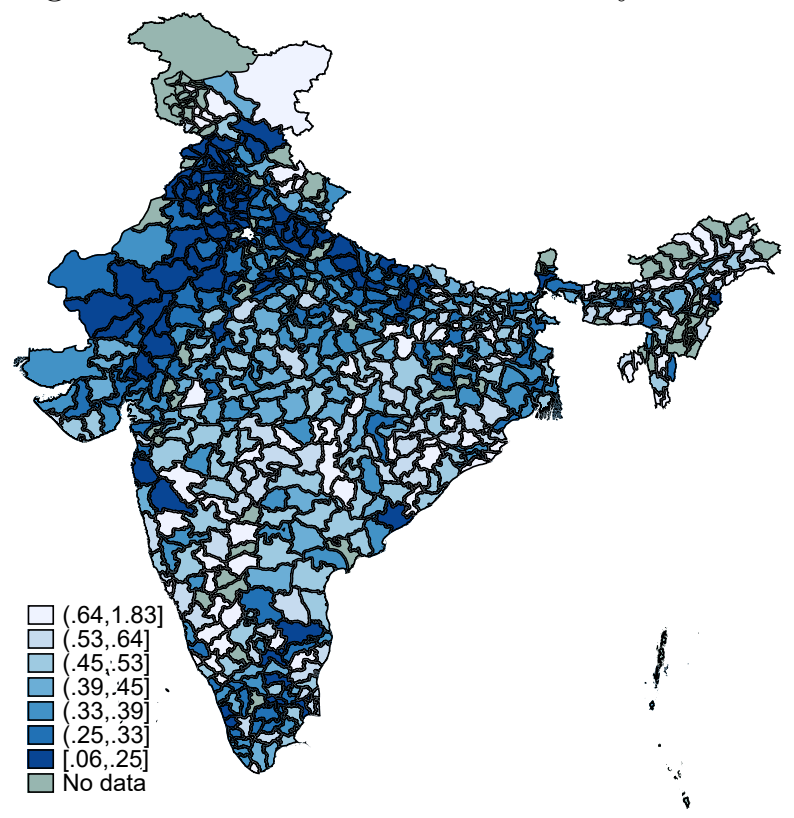

secularly growing or shrinking currency demand. However, the narrative record does not support the supposition that the RBI allocated new notes geographically in a manner determined by local economic conditions, at least for the first few months after demonetization. The official post-partum of the episode contained in the RBI's 2017 annual report (RBI, 2017a, p. 132) starts by acknowledging "the logistical difficulties in supplying banknotes to all currency chests in a short span," suggesting that logistical factors may have played a role in the geographic distribution. It continues: "Fresh notes were distributed to every Issue Office in accordance with a planned allocation. The Regional Office-wise allocation of notes was revised during the last quarter of 2016-17 [calendar quarter 2017Q1] based on the SBNs [demonetized notes] deposited and cash supplied in issue circles during the demonetization period." The RBI has not made public the particulars of the "planned allocation," but its sophistication would have been limited by the secrecy surrounding the policy prior to its announcement as very few officials even within the government knew of the policy ahead of time. Moreover, the RBI in October 2016 could not have known the precise geographic distribution of existing 500 and 1000 notes in circulation. The next sentence of the report indicates that the RBI did not begin to incorporate real-time feedback concerning the geographic distribution of demonetized notes or other currency demand factors until early in 2017. Thus, the narrative record comports with treating the geographic distribution of the 
demonetization shock as "as good as random" at least through December 2016 and probably afterward as well.

Finally, we look for statistical patterns that would suggest a distribution of new notes in a way correlated with our outcome variables. In the next section, we report figures showing the correlations of outcomes and the demonetization shock before November 2016 and find no evidence of pre-trends in the data. Here we report correlations of the $\log$ of $Z_{i, t}$ in December 2016 with other variables in our data set: 2015 GDP per capita, the 2015 share of GDP in agriculture, the distance from the district to the closest RBI office, bank penetration, population density, and demonetized notes per capita. The largest bivariate correlation is with demonetized currency per capita - more currency-intensive areas experienced slower replacement rates. This pattern could reflect a desire by the RBI to smooth the per capita allocation of new notes across areas or simply that the RBI did not know the geographic distribution of old notes in real time. There is no reason it would cause a violation of the parallel trends assumption. In what follows we will report specifications which control directly for GDP per capita, the agriculture share of GDP, and population density.

\section{Cross-sectional Results}

In this section we use the geographic variation in the net drop in cash due to demonetization to document the following results: (i) demonetization caused cash shortages, as evidenced by a sharper decline in ATM withdrawals in areas with larger shocks; (ii) economic activity, as measured by employment rates and nightlights, fell in these areas relative to areas experiencing smaller shocks; (iii) these areas adopted alternative forms of payment; and (iv) deposits increased more and credit fell in these areas. These results, which come from disparate data sources, together provide a consistent account of the effects of demonetization.

We emphasize at the outset three important advantages of the cross-sectional approach. First, it holds constant other policies or shocks affecting the whole economy around the period of demonetization. Moreover, even if other policies or shocks had differential effects across subnational areas, the cross-sectional approach will still uncover the causal effect of demonetization as long as the demonetization shock is uncorrelated with the geographic footprint of these other variables. Second, instead of a single time series with a possible break in November 2016, the geographic variation in demonetization intensity generates a large sample with varying treatment intensity. The large sample makes possible tighter inference. Third, the cross-sectional comparison isolates the component of demonetization 
Table 4: What is the Currency Shock Correlated With?

\begin{tabular}{|c|c|c|c|c|c|c|c|}
\hline & $(1)$ & (2) & (3) & (4) & (5) & (6) & (7) \\
\hline Log GDP per capita & $\begin{array}{c}-0.21 \\
(0.15)\end{array}$ & & & & & & $\begin{array}{c}0.02 \\
(0.22)\end{array}$ \\
\hline Agriculture share of GDP & & $\begin{array}{c}0.00 \\
(0.07)\end{array}$ & & & & & $\begin{array}{c}-0.13^{+} \\
(0.07)\end{array}$ \\
\hline Log distance to closest RBI office & & & $\begin{array}{c}0.13^{*} \\
(0.06)\end{array}$ & & & & $\begin{array}{c}-0.11 \\
(0.06)\end{array}$ \\
\hline Log bank branches per capita & & & & $\begin{array}{c}-0.21 \\
(0.12)\end{array}$ & & & $\begin{array}{c}-0.12 \\
(0.17)\end{array}$ \\
\hline Log population density & & & & & $\begin{array}{c}-0.32^{* *} \\
(0.10)\end{array}$ & & $\begin{array}{c}-0.39^{* *} \\
(0.12)\end{array}$ \\
\hline Log demonetized notes per capita & & & & & & $\begin{array}{c}-0.33^{* *} \\
(0.08)\end{array}$ & $\begin{array}{c}{ }^{*}-0.32^{* *} \\
(0.09)\end{array}$ \\
\hline BM df & 13.0 & 9 & 19 & 18 & 16 & 13.9 & \\
\hline$R^{2}$ & 0.04 & 0.00 & 0.0 & $0 .($ & 0.10 & 0.11 & 0.22 \\
\hline $\mathrm{C}$ & 31 & 31 & 33 & 31 & 31 & 31 & 31 \\
\hline Observations & 540 & 532 & 542 & 540 & 539 & 540 & 531 \\
\hline
\end{tabular}

Notes: The table reports the correlation coefficient (columns 1-5) and partial correlation coefficient (column 6 ) with $z_{i, t}$, the log of the demonetization shock. Standard errors in parentheses clustered by state using the bias-reduction modification suggested by Imbens and Kolesár (2016). The row gives the associated t-distribution degrees of freedom for the coefficient. ${ }^{* *}$ denotes significance at the 1 percent level.

due to the temporary unavailability of currency. While we believe this aspect to have been the dominant channel, in the next section we discuss other possible channels which might apply at the aggregate level.

\subsection{Cross-sectional Specification}

Our empirical specification is:

$$
\left(y_{i, t}-y_{i, \text { baseline }}\right)=\beta_{0, t}+\beta_{1, t} z_{i, \text { treatment }}+\Gamma_{t} X_{i}+\epsilon_{i, t},
$$

where $y_{i, t}$ denotes the natural logarithm of an outcome variable in district $i, y_{i, \text { baseline }}$ denotes the $\log$ of the variable in the period immediately preceding demonetization (October 2016 for monthly frequency data and 2016Q3 for quarterly frequency data), $z_{i, t}=\ln Z_{i, t}$ is the $\log$ of the demonetization shock, $z_{i, \text { treatment }}$ is set to $z_{i, t}$ for $t \in\{$ November 2016, December 2016\} 
and the December 2016 value for all other periods, and $X_{i}$ is a vector containing any controls. The coefficients $\beta_{1, t}$ trace out the cumulative response at various horizons $t$ to the demonetization shock in December 2016.

We offer three comments on specification (18). First, this specification cannot disentangle contemporaneous from lagged effects of the demonetization shock in months after December 2016. Rather, the coefficient $\beta_{1, t}$ reflects both the persistence in $z_{i, t}$ which makes $z_{i, \text { treatment }}$ correlated with $z_{i, t}$ for months after December 2016 and true lagged effects of $z_{i, \text { treatment }}$ on outcomes. We do not attempt to separate these effects because of the possible concern raised above that the distribution of new notes after December 2016 reflected contemporaneous factors and because in any case the stability of the rank of a district in the cross-sectional distribution of shocks over time yields too little variation to separately identify contemporaneous from lagged effects. ${ }^{22}$ Second, some of the dependent variables used in the analysis have wide tails. The log-log specification helps to reduce sensitivity to outliers. We further trim observations with dependent variable in the the top and bottom $0.5 \%$ of the distribution in the period of analysis. Third, we cluster standard errors by state to account for the spatial correlation in $Z_{i, t}$ shown in figure 5 . This level of clustering results in about 30 clusters. $^{23}$ We follow the advice of Imbens and Kolesár (2016) and apply the "LZ2" correction to the standard errors and compute confidence intervals using a t-distribution with degrees of freedom suggested by Bell and McCaffrey (2002). ${ }^{24}$ Imbens and Kolesár (2016, table 4) present Monte Carlo evidence that the resulting confidence intervals have good coverage even with as few as five clusters or unbalanced cluster size.

\subsection{Results}

ATM withdrawals. Figure 6 and table 5 show our first result - areas that received (proportionally) fewer new notes had sharper declines in ATM activity. The left panel

\footnotetext{
${ }^{22}$ For example, the Spearman rank correlation of $z_{i}$ for December 2016 and March 2017 is 0.80.

${ }^{23}$ India consists of 29 states and 7 union territories and we use the term "state" in the main text to refer to either. We assign districts in Telangana to the same cluster as districts in Andhra Pradesh (the former was carved out of the latter in 2014 and both states share a single RBI regional office located in Hyderabad), have no currency chest data for the territory of Dadra and Nagar Haveli, and exclude the territory of Chandigarh because it has $Z_{i, t}<0$. Therefore, the regressions that follow have a maximum of 33 clusters. In specifications controlling for 2015 GDP per capita, we further drop the two union territories of Daman \& Diu and Lakshadweep due to lack of GDP data.

${ }^{24}$ The LZ2 correction applies a small sample adjustment that exactly corrects for finite sample bias in the sample counterpart of $E\left[\epsilon_{i, t} \epsilon_{i, t}^{\prime}\right]$ when the true sampling distribution of $\epsilon_{i, t}$ is i.i.d. The degrees of freedom for the t-distribution are chosen such that under homoskedasticity the first two moments of the distribution of the error covariance matrix coincide with the first two moments of a chi-squared distribution.
} 
Figure 6: ATM Withdrawals
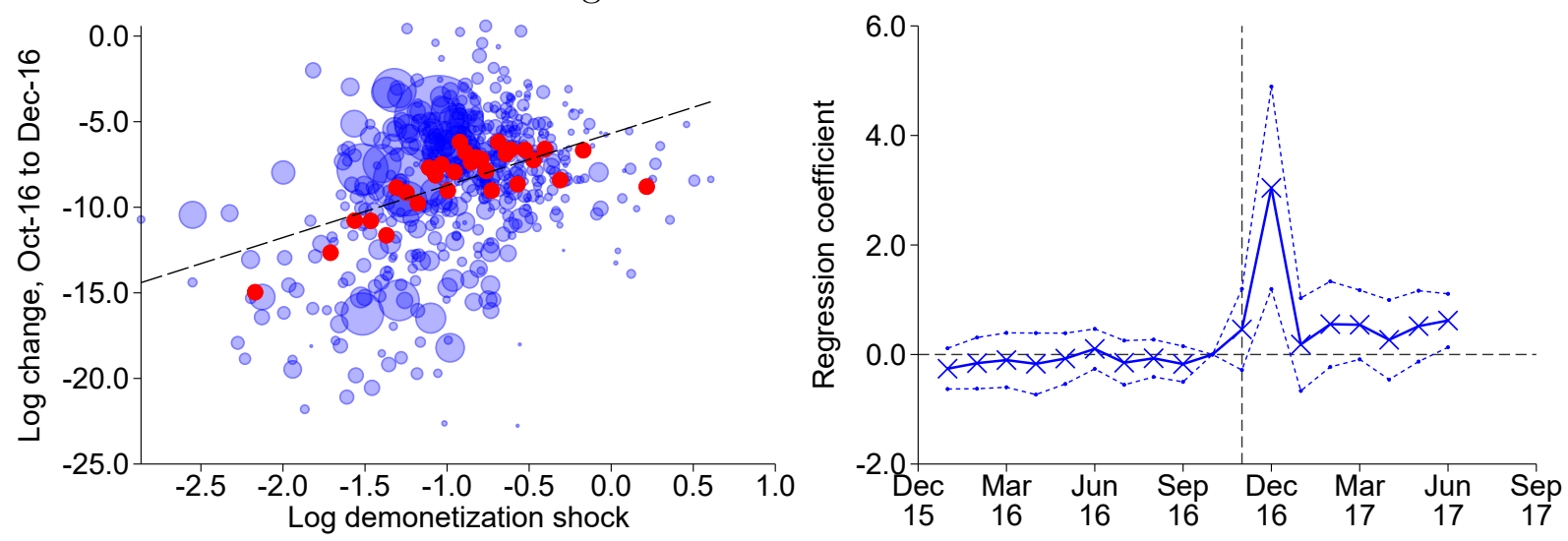

Notes: The left panel presents a scatter plot of the log change in ATM withdrawals between October 2016 and December 2016 and the log demonetization shock. The light blue circles show the raw data and are sized proportional to 2015 district GDP. The dark red circles average observations into 30 quantile bins of the currency shock. The dashed line gives the best fit line. The right panel reports the coefficient and $95 \%$ confidence interval from estimating equation (18) for the period indicated on the horizontal axis.

provides a non-parametric representation of the data. The vertical axis gives the log change in ATM activity from October 2016, the last full pre-demonetization month, to December 2016, the first full month following demonetization. The horizontal axis shows $z_{i, t}$, the $\log$ of the average daily value in December 2016 of the demonetization measure described by equation (10). Each blue circle corresponds to a district, with the size of the circle proportional to 2015 district GDP. The red circles show the (unweighted) means of the change in ATM activity for each of 30 quantile bins of $z_{i, t}$. Thus, the figure overlays a "binned scatter plot" on top of the raw data. The dashed red line shows the best fit line.

The right panel of figure 6 reports the coefficient from estimating equation (18) with no covariates in $X_{i}$ for each month from November 2015 to June 2017. Thus, the value for December 2016 gives the slope of the best fit line in the figure in the left panel. The dashed lines show the (point-wise) 95\% confidence intervals.

The figure shows a statistically strong, positive correlation between the arrival of new currency by December 2016 and ATM withdrawals. The link between money supply and cash withdrawals validates the usefulness of our geographic shock measure and provides prima facie evidence of a cash shortfall in which households are off their money demand curve. The near-zero values in the right panel for months before November 2016 indicate that districts which experienced larger demonetization shocks exhibited parallel trend growth of ATM withdrawals before the shock occurred. The cross-sectional impact of the shock on ATM withdrawals is concentrated in December 2016 but remains through June 2017. In terms of 
Table 5: ATM Withdrawals

\begin{tabular}{lccc}
\hline \hline & $(1)$ & $(2)$ & $(3)$ \\
\hline Demonetization shock & $3.04^{* *}$ & $2.86^{* *}$ & $3.08^{*}$ \\
& $(0.85)$ & $(0.92)$ & $(1.12)$ \\
Log GDP per capita & & 0.04 & 0.17 \\
& & $(0.85)$ & $(0.76)$ \\
Agriculture share of GDP & & 0.02 & -0.01 \\
& & $(0.03)$ & $(0.03)$ \\
Log population density & & -0.39 & -0.04 \\
& No & $(0.43)$ & $(0.29)$ \\
\hline Control lagged outcomes & No & No & Yes \\
Weight & 35.3 & 33.2 & 35.8 \\
Fitted 90-10 differential & 12.8 & 14.6 & 12.8 \\
Treatment BM df & 0.13 & 0.18 & 0.17 \\
$R^{2}$ & 33 & 31 & 31 \\
Clusters & 531 & 521 & 521 \\
Observations &
\end{tabular}

Notes: The dependent variable is the log point change from October 2016 to December 2016 multiplied by 10. Columns (2) and (3) additionally controls for 9 lags of the dependent variable. Column (3) weights the regression by district GDP. Standard errors in parentheses clustered by state using the "LZ2" biasreduction modification suggested by Imbens and Kolesár (2016). ${ }^{* *},{ }^{*},{ }^{+}$denote significance at the 1,5 , or 10 percent level based on a t-distribution with degrees of freedom for the demonetization shock shown in the row "Treatment BM df".

magnitude, the predicted difference in ATM withdrawals between districts at the 10th and 90th percentiles of the December 2016 shock distribution is 37 log points.

Table 5 demonstrates the robustness of the cross-sectional pattern. Column (1) reproduces the slope coefficient from the left panel of figure 6. Column (2) adds covariates to the regression: 2015 GDP per capita, the 2015 agriculture share of GDP, log population density, and nine lags of ATM transactions growth. The lags of ATM growth control directly for any pre-trends while the 2015 level of GDP per capita and agriculture share of GDP control for basic features of the industrial structure of Indian districts. As shown in table 4, population density correlates with the demonetization shock. Yet, inclusion of these covariates has little effect on the coefficient on $z_{i, t}$.

Column (3) weights the regression by district GDP. The coefficient changes little. Weighting would be appropriate if larger districts had less measurement error or if the effect of a given amount of demonetization varied with district size (Solon, Haider, and Wooldridge, 2015). The stability of the standard error in the weighted specification militates against the 
efficiency rationale. The small change in the point estimate suggests that weighting due to heterogeneous treatment effects is unnecessary. Appendix B.4 further explores heterogeneous treatment effects by interacting $z_{i, t}$ with other variables and shows economically small and statistically insignificant interaction coefficients.

Employment and nightlights. Figure 7 and table 6 display our next main result - demonetization reduced real economic activity. The scatter plots in the left panels of figure 7 show non-parametrically that areas with larger declines in currency experienced sharper declines in employment and in nightlight activity after demonetization occurred. The right panels show no evidence of pre-trends and highly statistically significant post-demonetization differences, which last into the spring of 2017 before fully dissipating as all areas get remonetized. ${ }^{25}$

The magnitude of the effect on real activity is substantial. The predicted difference in employment growth between districts at the 10th and 90th percentiles immediately after demonetization is $4.0 \mathrm{log}$ points while the predicted difference in nightlight growth is 14.0 $\log$ points. ${ }^{26}$ Based on both annual and long-term growth rate comparisons for a sample of 188 countries, Henderson, Storeygard, and Weil (2012) argue for an elasticity of GDP growth to nightlight growth of 0.3. Their estimate remains similar even for a sub-sample of low and middle-income countries. Using this elasticity yields a predicted difference in GDP of roughly $4.2 \log$ points. It bears emphasizing that these two measures of economic activity come from very different sources - a household survey of employment status and satellite measures of nightlight activity - yet they suggest quantitatively similar declines in output. The two measures together therefore provide powerful evidence of a link between money and output during demonetization. ${ }^{27}$

\footnotetext{
${ }^{25}$ Recall that the employment survey uses a rotation schedule such that each month contains data for only about 150 districts. For this reason, the top left panel of table 6 pools observations from December 2016, January 2017, and February 2017 in order to obtain a more complete sample of districts and the top right panel shows coefficients grouping months with the same sample units. Because the data start in January 2016, the first point shown in the top right panel contains data from two rather than three months, explaining the wider confidence interval around that point.

${ }^{26}$ Technically, the predicted difference in the growth rate of the employment-to-population ratio is $4.0 \log$ points. Recall that the household survey data from which we calculate the employment-to-population ratio do not permit measurement of the change in population. Assuming zero effect of demonetization on population, the predicted difference in the growth rate of the employment-to-population ratio is also the predicted difference in the growth rate of employment. We believe such an assumption to be reasonable given the short time horizon over which demonetization occurred. Nonetheless, if in fact more severe demonetization in an area led to worker outflows, then the effect on employment would be larger than the 4.0 log point difference given in the main text.

${ }^{27}$ Table B.1 in the online appendix shows that the nightlight response reflects differential patterns of
} 
Figure 7: Real Activity

Panel A: Employment
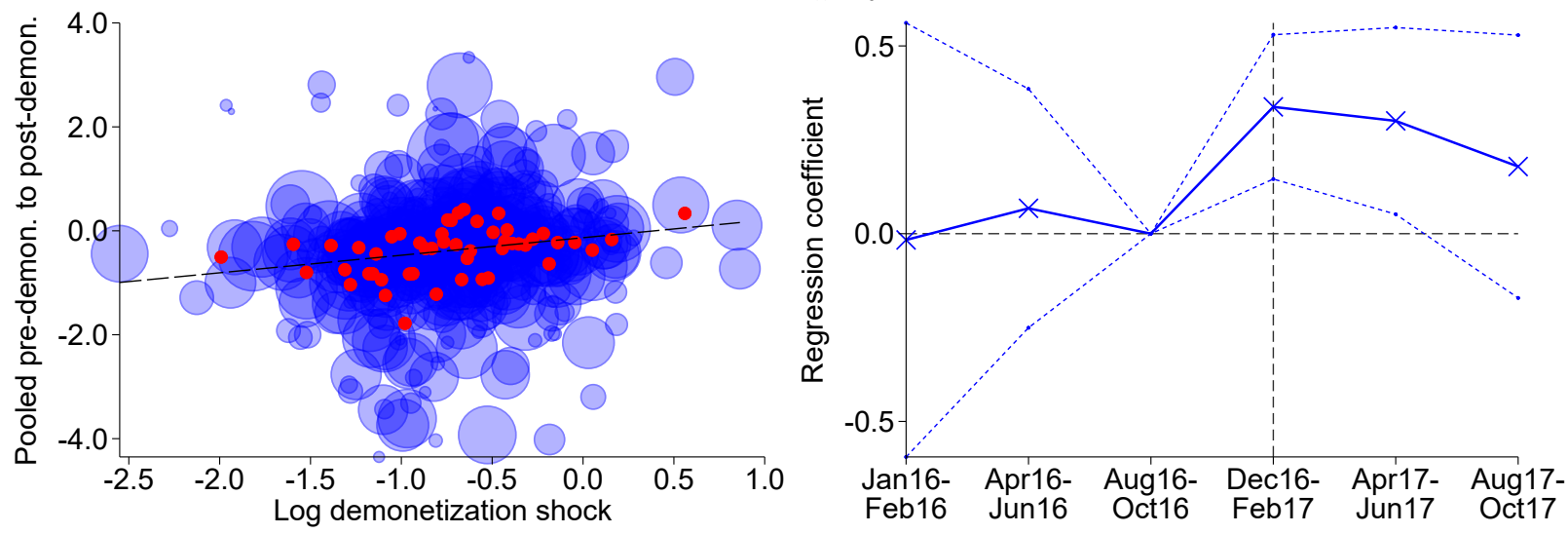

Panel B: Nightlights
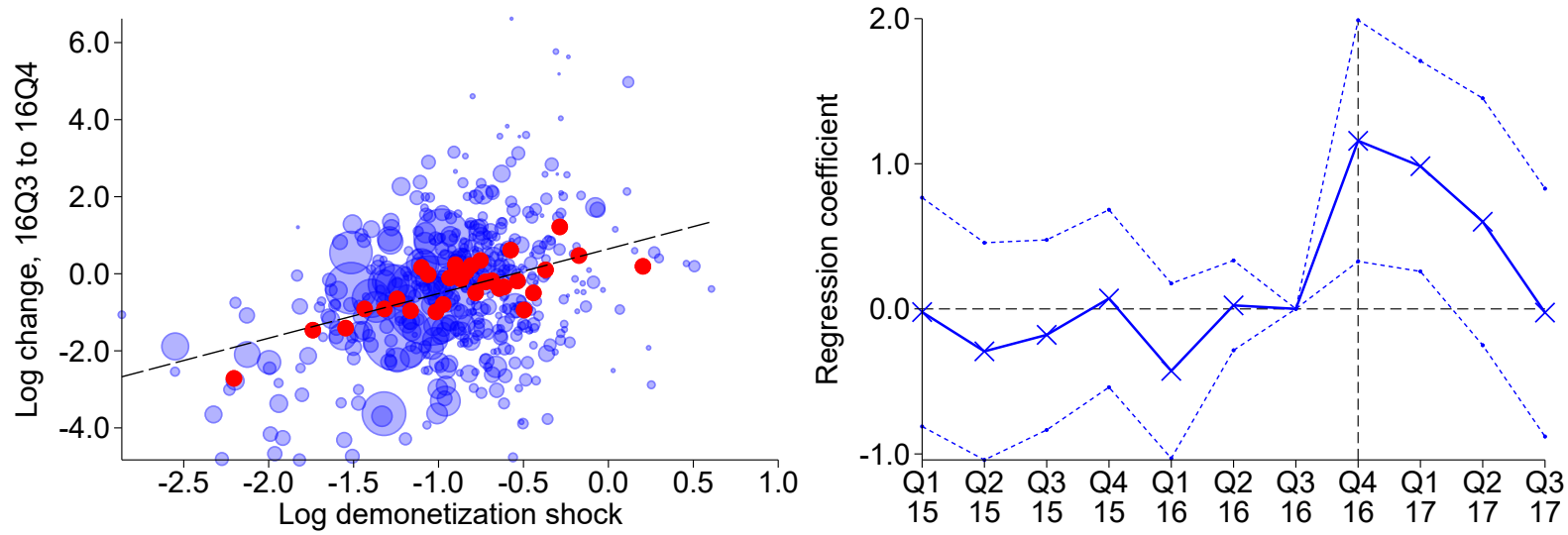

Notes: The top left panel presents a scatter plot of the log change in the employment-to-population ratio relative to the last observation before November 2016 and the log demonetization shock and pools observations from December 2016, January 2017, and February 2017. The bottom left panel presents a scatter plot of the log change in nightlight activity between July to September 2016 and November-December 2016 and the log demonetization shock. The light blue circles show the raw data and are sized proportional to 2015 district GDP. The dark red circles average observations into 30 quantile bins of the currency shock. The dashed line gives the best fit line. The right panels report the coefficients and $95 \%$ confidence intervals from estimating equation (18) for the period indicated on the horizontal axis.

The remainder of table 6 illustrates the robustness of the employment and nightlight results. Columns (2) and (5) show robustness to controlling for lagged outcomes and the

electricity consumption. Quarterly data on electricity consumption by district do not exist. Instead, we use state-level data on electricity consumption and show (i) the cross-district relationship between nightlight growth in 2016Q4 and demonetization severity also holds at the state level; (ii) there is a strong cross-state relationship between nightlight growth and growth of electricity consumption; and (iii) after controlling for electricity consumption, there is no relationship between nightlight growth and demonetization severity. This last result is exactly what should happen if nightlight growth is related to demonetization only because electricity consumption is related to demonetization. 
Table 6: Real Activity

\begin{tabular}{|c|c|c|c|c|c|c|c|}
\hline \multirow[t]{2}{*}{ Dep. var.: log change in } & \multicolumn{3}{|c|}{ Employment } & \multicolumn{4}{|c|}{ Nightlights } \\
\hline & (1) & (2) & (3) & (4) & (5) & (6) & (7) \\
\hline \multirow[t]{2}{*}{ Demonetization shock } & $0.34^{* *}$ & $0.47^{* *}$ & 0.22 & $1.20^{* *}$ & $1.15^{* *}$ & $1.44^{*}$ & $1.19^{* *}$ \\
\hline & $(0.09)$ & $(0.08)$ & $(0.16)$ & $(0.37)$ & $(0.34)$ & $(0.46)$ & $(0.31)$ \\
\hline \multirow[t]{2}{*}{ Log GDP per capita } & & $0.22^{+}$ & 0.04 & & -0.25 & 0.22 & \\
\hline & & $(0.11)$ & $(0.25)$ & & $(0.20)$ & $(0.30)$ & \\
\hline \multirow[t]{2}{*}{ Agriculture share of GDP } & & 0.00 & 0.00 & & 0.01 & -0.00 & \\
\hline & & $(0.00)$ & $(0.00)$ & & $(0.01)$ & $(0.01)$ & \\
\hline \multirow{2}{*}{ Lop population density } & & $0.11^{+}$ & 0.03 & & 0.03 & -0.18 & \\
\hline & & $(0.05)$ & $(0.07)$ & & $(0.10)$ & $(0.23)$ & \\
\hline Control lagged ou & No & Yes & Yes & No & Yes & Yes & No \\
\hline Month span FE & No & Yes & Ye & No & No & No & No \\
\hline Weight & Yes & Yes & No & No & No & Yes & No \\
\hline Fitted 90-10 differential & 4.0 & 5.6 & 2.6 & 14.0 & 13.3 & 16.7 & 13.9 \\
\hline Treatment BM df & 9.9 & 11.4 & 12.3 & 11.4 & 13.7 & 9.5 & 12.8 \\
\hline$R^{2}$ & 0.03 & 0.30 & 0.21 & 0.11 & 0.50 & 0.49 & 0.10 \\
\hline Clusters & 22 & 22 & 22 & 32 & 30 & 30 & 33 \\
\hline Observations & 407 & 396 & 396 & 473 & 464 & 464 & 537 \\
\hline
\end{tabular}

Notes: The dependent variable is the log point change from pre-demonetization to post-demonetization multiplied by 10. In columns (1)-(3) the sample pools all observations from December 2016 to February 2017. In columns (4)-(6) the sample includes observations from December 2016, excluding districts in Uttar Pradesh. Column (7) adds these districts to the sample. Columns (2), (3), (5), (6) additionally control for lags of the dependent variable. Columns (1) and (2) weight the regression by the number of individual observations in the district in the Consumer Pyramids data and column (6) weights the regression by district GDP. Standard errors in parentheses clustered by state using the "LZ2" bias-reduction modification suggested by Imbens and Kolesár (2016). ${ }^{* *},{ }^{*},{ }^{+}$denote significance at the 1,5 , or 10 percent level based on a tdistribution with degrees of freedom for the demonetization shock shown in the row "Treatment BM df".

level of GDP per capita and the agriculture sectoral share. Columns (3) and (6) show robustness to weighting or not. For employment, we weight the baseline specification by the number of individual-level observations in the district-month to reflect the construction of the district employment variable from individual-level data. Column (3) shows that not weighting increases the standard error substantially, consistent with a noisier measure of employment for districts with fewer individual observations. Finally, our baseline sample for nightlight activity only excludes districts in the state of Uttar Pradesh because they exhibit implausible growth of human-generated nightlights between 2016Q4 and 2017Q1. Column (7) shows that including these districts has essentially no effect on the estimated effect on 
nightlight activity in $2016 \mathrm{Q} 4 .^{28}$

POS and E-Wallet. The next set of results in figure 8 and table 7 show the shift to alternative payment technologies. Payments using both E-Wallet and POS increased more in districts experiencing sharper declines in money following demonetization. Thus, while these areas experienced declines in overall economic activity and ATM usage, they had faster growth of alternative payments mechanisms. This pattern strongly militates against the presence of an unobserved demand shock confounding our identification, as a pure demand shock would induce positive comovement across all payments mechanisms and output. While the e-wallet data start only in September 2016, limiting our ability to test for pre-trends, the POS data show no differential adoption during the pre-demonetization period.

Table 7 shows robustness to the usual specification perturbations. The e-wallet results are highly robust and all statistically significant. The standard errors in the POS regressions are much larger, such that the coefficient on $z_{i, t}$ is significant only at the $10 \%$ level in the weighted specification.

Deposits and Credit. Figure 9 and table 8 report our final set of results covering bank deposit and credit growth. We find evidence of bank deposits increasing and credit contracting in areas experiencing more severe demonetization. The effect on deposits appears short-lived while the effect on credit may be more persistent. Because banks have access to internal credit markets and banks in more-demonetized districts experienced faster deposit growth, we can interpret the contraction in lending in those districts as due to lower borrower demand for credit. As a caveat to these results, recall that the credit variable corresponds to loans made by banks within a district regardless of the location of the borrower. These results appear broadly robust to alternative specifications.

\section{Discussion and Relation to Aggregate Impact}

The cross-sectional results establish that areas experiencing more severe demonetization had sharper declines in ATM withdrawals, reduced economic activity, faster adoption of

\footnotetext{
${ }^{28}$ The median quarterly growth rate among districts in Uttar Pradesh in 2017Q1 was 64 log points, equal to the 99th percentile quarterly growth rate for all other districts pooling over all quarters between 2015Q4 and 2017Q3. A possible explanation for the behavior of nightlights in 2017Q1 is that Uttar Pradesh held statewide elections in February and March of 2017 and the ruling party accelerated electrification in the run-up to the election.
} 
Figure 8: Alternative Forms of Payment
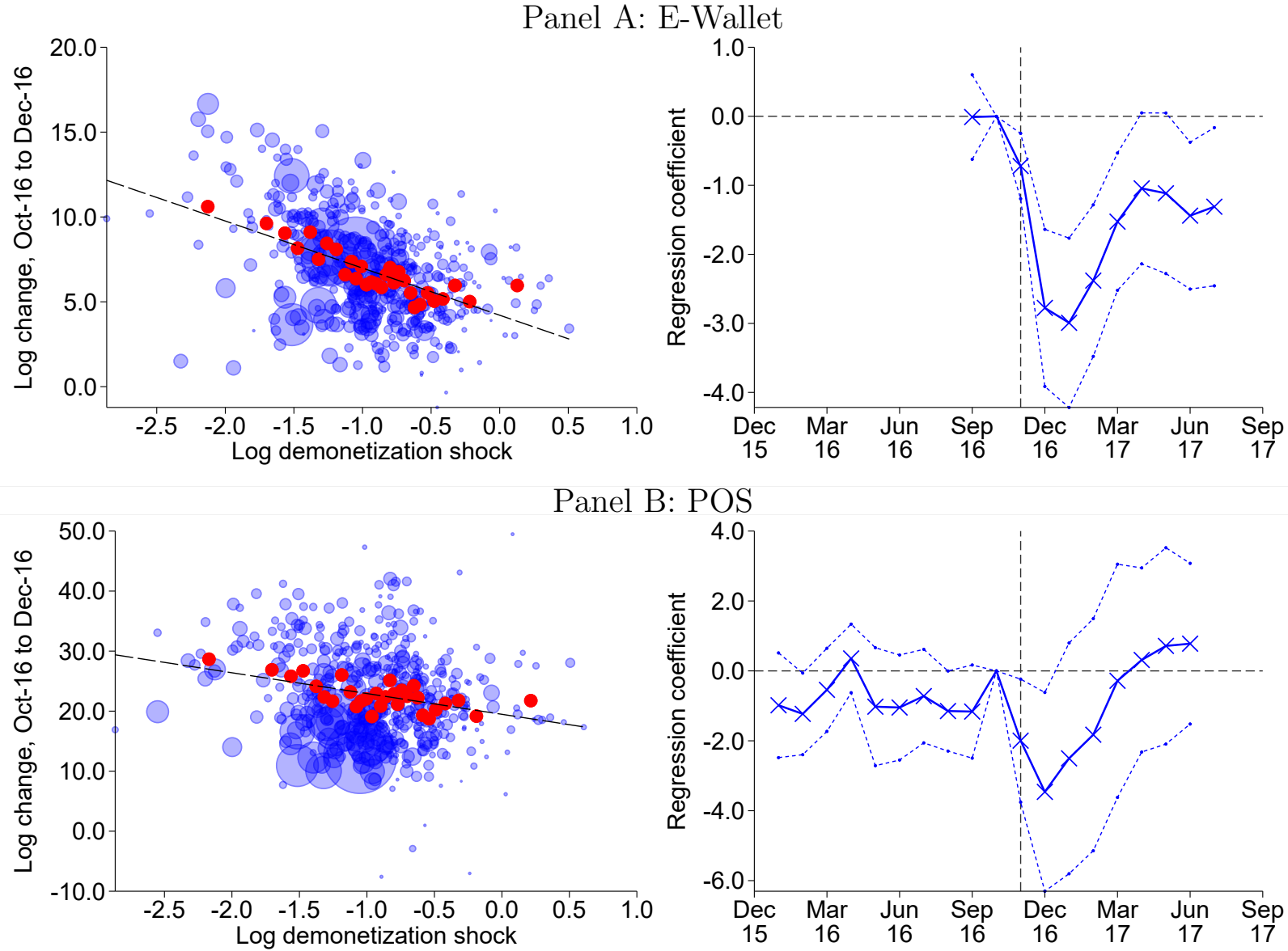

Notes: The left panels present scatter plots of the log change in e-wallet transactions (top row) or POS transactions (bottom row) between October 2016 and December 2016 and the log demonetization shock. The light blue circles show the raw data and are sized proportional to 2015 district GDP. The dark red circles average observations into 30 quantile bins of the currency shock. The dashed line gives the best fit line. The right panels report the coefficients and $95 \%$ confidence intervals from estimating equation (18) for the period indicated on the horizontal axis.

alternative payment technologies, and higher deposit and lower bank credit growth. These cross-sectional patterns reject monetary neutrality and the cashless limit in the context of India's demonetization.

We now turn to the effect on aggregate economic activity. We first report time series aggregates around demonetization. Then, we discuss how the cross-sectional evidence informs about the aggregate impact of demonetization. 
Table 7: Alternative Forms of Payment, Dec-16

\begin{tabular}{|c|c|c|c|c|c|c|}
\hline \multirow[t]{2}{*}{ Dep. var.: log change in } & \multicolumn{3}{|c|}{ E-Wallet } & \multicolumn{3}{|c|}{ POS } \\
\hline & (1) & (2) & (3) & (4) & (5) & (6) \\
\hline Demonetization shock & $\begin{array}{c}-2.78^{* *} \\
(0.53)\end{array}$ & $\begin{array}{c}-2.99^{* *} \\
(0.47)\end{array}$ & $\begin{array}{c}-3.41^{* *} \\
(0.69)\end{array}$ & $\begin{array}{r}-3.46^{*} \\
(1.31)\end{array}$ & $\begin{array}{c}-4.24^{* *} \\
(1.38)\end{array}$ & $\begin{array}{r}-3.50^{+} \\
(1.71)\end{array}$ \\
\hline Log GDP per capita & & $\begin{array}{c}-0.74 \\
(0.57)\end{array}$ & $\begin{array}{c}-0.41 \\
(0.50)\end{array}$ & & $\begin{array}{c}-2.57^{* *} \\
(0.80)\end{array}$ & $\begin{array}{c}-3.23^{* *} \\
(0.72)\end{array}$ \\
\hline Agriculture share of GDP & & $\begin{array}{c}0.01 \\
(0.02)\end{array}$ & $\begin{array}{c}0.02 \\
(0.02)\end{array}$ & & $\begin{array}{c}0.14^{* *} \\
(0.02)\end{array}$ & $\begin{array}{c}0.19^{* *} \\
(0.03)\end{array}$ \\
\hline Log population density & & $\begin{array}{c}0.12 \\
(0.32) \\
\end{array}$ & $\begin{array}{c}0.14 \\
(0.23) \\
\end{array}$ & & $\begin{array}{r}-1.53^{*} \\
(0.55) \\
\end{array}$ & $\begin{array}{r}-1.16 \\
(0.90) \\
\end{array}$ \\
\hline Control lagged outcomes & No & Yes & Yes & No & Yes & Yes \\
\hline Weight & No & No & Yes & No & No & Yes \\
\hline Fitted 90-10 differential & -32.2 & -34.7 & -39.6 & -40.2 & -49.3 & -40.6 \\
\hline Treatment BM df & 13.0 & 13.3 & 11.6 & 12.3 & 13.9 & 9.8 \\
\hline$R^{2}$ & 0.20 & 0.24 & 0.23 & 0.05 & 0.31 & 0.40 \\
\hline Clusters & 30 & 29 & 29 & 33 & 31 & 31 \\
\hline Observations & 512 & 503 & 503 & 522 & 499 & 499 \\
\hline
\end{tabular}

Notes: The dependent variable is the log point change from October 2016 to December 2016 multiplied by 10. Columns (2), (3), (5), (6) additionally control for lags of the dependent variable. Columns (3) and (6) weight the regression by district GDP. Standard errors in parentheses clustered by state using the "LZ2" bias-reduction modification suggested by Imbens and Kolesár $(2016) .{ }^{* *},{ }^{*},+$ denote significance at the 1, 5, or 10 percent level based on a t-distribution with degrees of freedom for the demonetization shock shown in the row "Treatment BM df".

\subsection{Aggregate Time Series}

Figure 10 plots time series aggregates around demonetization. The vertical line in each figure shows the period in which demonetization occurred. In interpreting these figures, it is important to keep in mind that other economic shocks and policies besides demonetization also affected the global economy and India specifically during this period, factors that the cross-sectional approach could ignore. Salient examples include the election of Donald Trump on the same day as the demonetization announcement, a rise in the global price of crude oil of $60 \%$ from January to October 2016, a better Monsoon rainfall than in the previous year, increased uncertainty related to capital flows into Foreign Currency Non-Repatriable accounts and accompanying exchange rate volatility in November 2016, and an overhaul of the Indian sales tax collection system in the summer of 2017.

These caveats aside, aggregate ATM withdrawals, e-wallet use, and POS payment trans- 
Figure 9: Bank Deposits and Credit

Panel A: Deposits
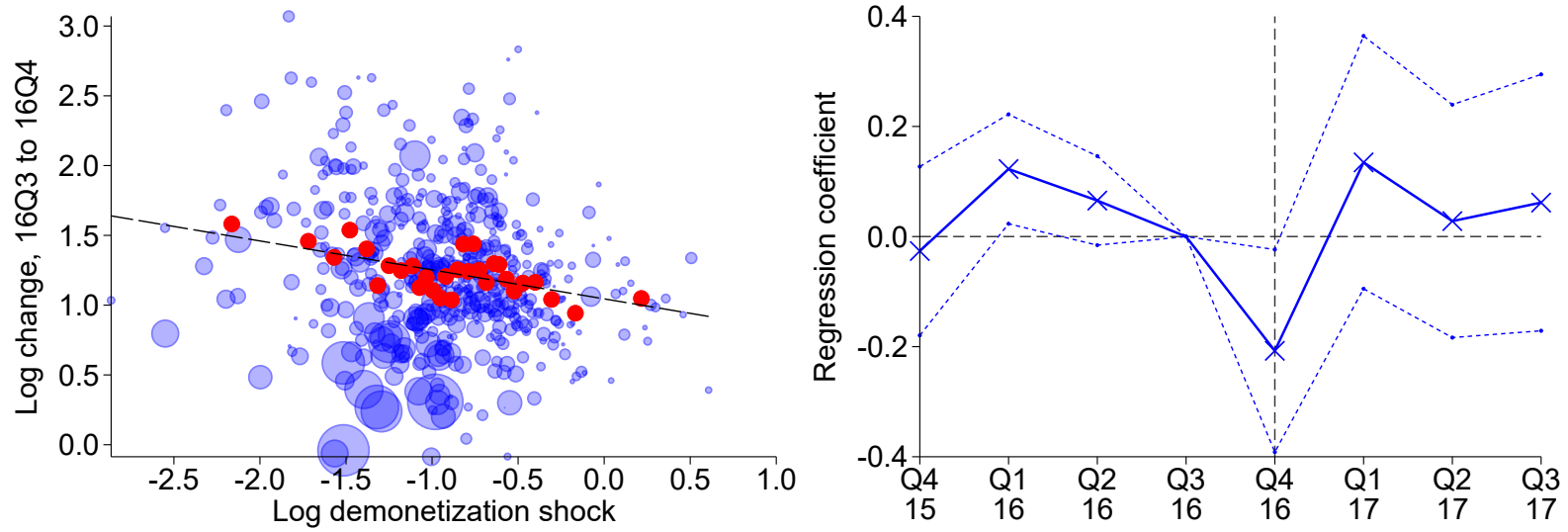

Panel B: Credit
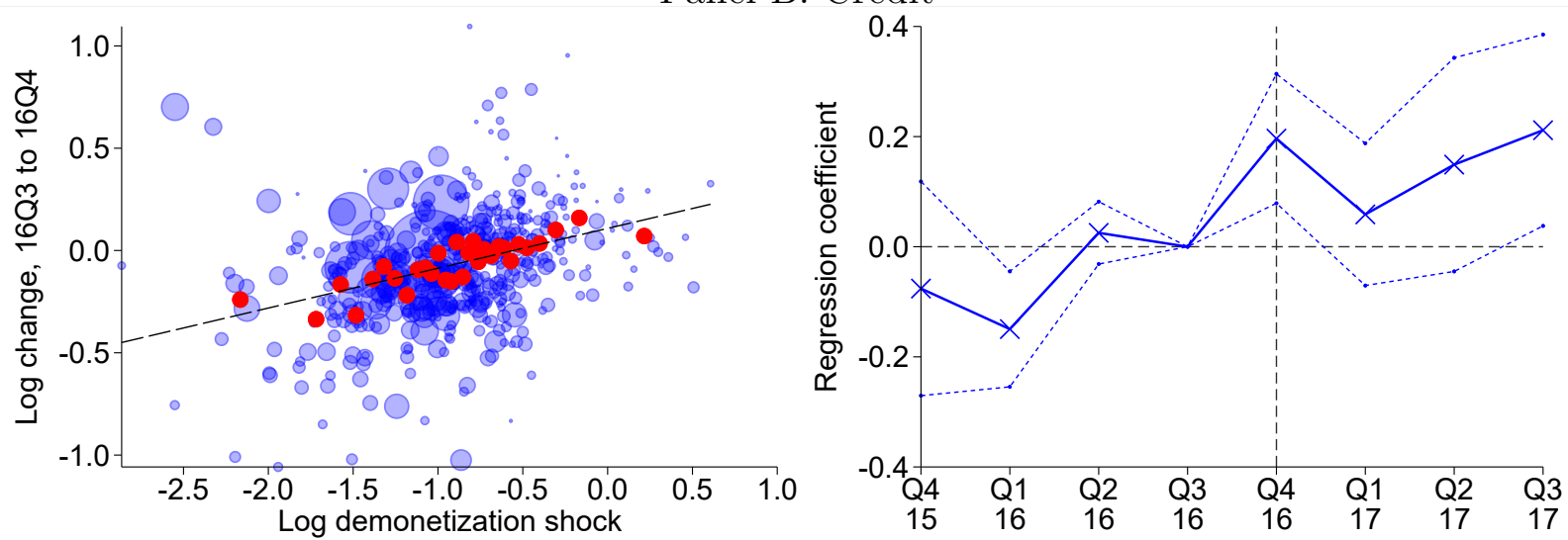

Notes: The left panels present scatter plots of the log change in deposits (top row) or credit (bottom row) between 2016Q3 and 2016Q4 and the log demonetization shock. The light blue circles show the raw data and are sized proportional to 2015 district GDP. The dark red circles average observations into 30 quantile bins of the currency shock. The dashed line gives the best fit line. The right panels report the coefficients and $95 \%$ confidence intervals from estimating equation (18) for the period indicated on the horizontal axis.

actions all exhibit essentially no growth in the periods before demonetization and then a sharp contraction (ATM withdrawals) or increase (e-wallet and POS) exactly at the time demonetization occurred. The scale of the changes in these variables - a $50 \%$ decline in ATM withdrawals, a doubling of e-wallet transactions, and a sextupling of POS transactions between October and December 2016 - seem difficult to attribute to any economic shock other than demonetization. ${ }^{29}$

In contrast, the variables representing aggregate real economic activity - GDP growth, employment, and nightlights - do not exhibit clear patterns around demonetization, nor do

\footnotetext{
${ }^{29}$ Because the wallet company provided us the data only in index format, the e-wallet panel of figure 10 shows an unweighted average across districts.
} 
Table 8: Bank Deposits and Credit, 2016Q4

\begin{tabular}{|c|c|c|c|c|c|c|}
\hline \multirow[t]{2}{*}{ Dep. var.: log change in } & \multicolumn{3}{|c|}{ Deposits } & \multicolumn{3}{|c|}{ Credit } \\
\hline & (1) & $(2)$ & $(3)$ & $(4)$ & $(5)$ & (6) \\
\hline \multirow[t]{2}{*}{ Demonetization shock } & $-0.21^{*}$ & $-0.35^{* *}$ & $-0.30^{*}$ & $0.20^{* *}$ & $0.14^{* *}$ & $0.09^{+}$ \\
\hline & $(0.09)$ & $(0.10)$ & $(0.11)$ & $(0.05)$ & $(0.04)$ & $(0.05)$ \\
\hline \multirow[t]{2}{*}{ Log GDP per capita } & & $-0.25^{* *}$ & $-0.28^{* *}$ & & -0.00 & $0.07^{+}$ \\
\hline & & $(0.06)$ & $(0.05)$ & & $(0.03)$ & $(0.04)$ \\
\hline \multirow[t]{2}{*}{ Agriculture share of GDP } & & $0.01^{* *}$ & $0.01^{* *}$ & & $-0.00^{* *}$ & $-0.00^{*}$ \\
\hline & & $(0.00)$ & $(0.00)$ & & $(0.00)$ & $(0.00)$ \\
\hline \multirow[t]{2}{*}{ Log population density } & & $-0.10^{+}$ & $-0.15^{* *}$ & & $-0.06^{*}$ & -0.01 \\
\hline & & $(0.05)$ & $(0.04)$ & & $(0.02)$ & $(0.03)$ \\
\hline Control lagged outcomes & No & Yes & Yes & No & Yes & Yes \\
\hline Weight & No & No & Yes & No & No & Yes \\
\hline Fitted 90-10 differential & -2.4 & -4.0 & -3.5 & 2.3 & 1.6 & 1.1 \\
\hline Treatment BM df & 12.9 & 13.9 & 10.4 & 13.2 & 14.9 & 11.7 \\
\hline$R^{2}$ & 0.04 & 0.29 & 0.43 & 0.11 & 0.25 & 0.24 \\
\hline Clusters & 32 & 30 & 30 & 32 & 30 & 30 \\
\hline Observations & 531 & 521 & 521 & 531 & 520 & 520 \\
\hline
\end{tabular}

Notes: The dependent variable is the log point change from 2016Q3 to 2016Q4 multiplied by 10. Columns (2), (3), (5), (6) additionally control for lags of the dependent variable. Columns (3) and (6) weight the regression by district GDP. Standard errors in parentheses clustered by state using the "LZ2" bias-reduction modification suggested by Imbens and Kolesár (2016). ${ }^{* *},{ }^{*},{ }^{+}$denote significance at the 1,5 , or 10 percent level based on a t-distribution with degrees of freedom for the demonetization shock shown in the row "Treatment BM df".

bank deposits or credit. ${ }^{30}$ The apparent insensitivity of GDP could reflect offsetting shocks at the aggregate level. As well, and importantly, while the level of GDP includes an estimate of informal sector activity derived from a quinquennial survey, quarterly changes in GDP do not reflect any direct measurement of informal sector activity. ${ }^{31}$ The informal sector in India

\footnotetext{
${ }^{30}$ Rural wage inflation (the only high frequency wage series available) and consumer price inflation remained positive and showed no discernible change in trend around demonetization. This is consistent with the model's assumption of downward wage and therefore price rigidity.

${ }^{31}$ The level of output of the informal sector in a base year is obtained from the quinquennial National Sample Survey of Unincorporated Enterprises. The survey in use at the time of writing was conducted in 2010-2011. Output of the informal sector in subsequent years is projected forward based on other indicators. For manufacturing, the indicator is the growth of formal sector manufacturing as measured in the Annual Survey of Industries (when it becomes available) or the index of industrial production. For services, the indicators are growth rates of sales taxes and service taxes, which reflect a combination of changes in compliance and real activity (CSO, 2015). Thus, even annual GDP does not incorporate direct measures of informal sector activity. In addition, quarterly GDP relies on a subset of the source data to allocate annual GDP across quarters. These indicators, such as the monthly industrial production index, mostly cover the largest formal sector establishments. Other high frequency economic indicators show sharper declines
} 
Figure 10: Aggregate Time Series
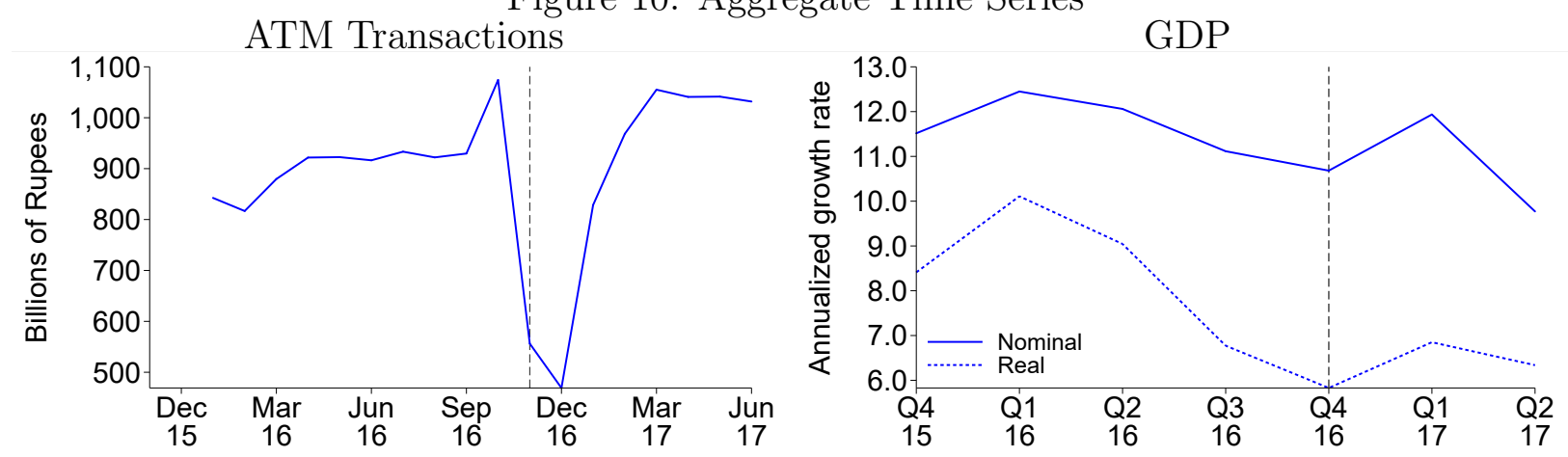

Employment/Population
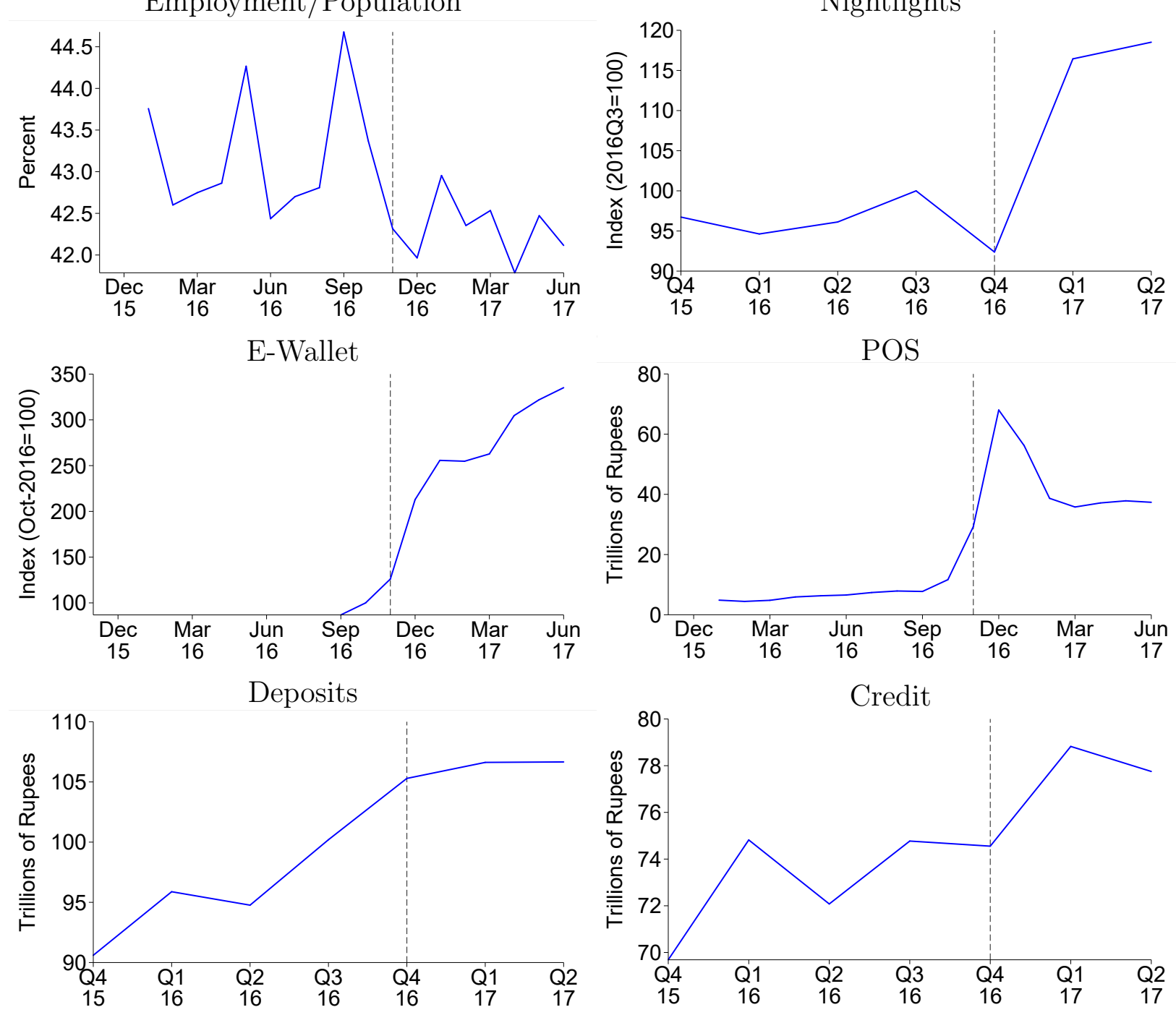

Notes: The dashed line in each figure denotes the month or quarter in which demonetization occurred.

in activity than does GDP (Goldman Sachs, 2017). As an additional complication, India does not report seasonally-adjusted quarterly GDP. The data in figuge 10 come from the OECD. 
is estimated to account for $81 \%$ of total employment (ILO, 2018) and $44 \%$ of total output (CSO, 2018) and is especially cash-intensive and therefore likely to have been affected by demonetization. In fact, the government itself concluded that official GDP would understate the impact of demonetization. CEA (2017, p. 19), the annual report written by the chief economist of the Government of India, states: "Recorded GDP growth in the second half of FY2017 will understate the overall impact [of demonetization] because the most affected parts of the economy — informal and cash-based — are either not captured in the national income accounts or to the extent they are, their measurement is based on formal sector indicators. For example, informal manufacturing is proxied by the Index of Industrial Production, which includes mostly large establishments. So, on the production or supply side, the effect on economic activity will be underestimated." Further, if demonetization pushed

some activity from the informal to the formal sector, official GDP could have spuriously risen.

Employment and nightlight activity better reflect the informal sector but have distinct drawbacks at the aggregate level. For employment, the short time series of the data precludes seasonal adjustment. For nightlight activity, changes in long-run factors such as electric capacity and measurement error in the procedure for removing stray light can generate changes in nightlight activity unrelated to high frequency economic activity. Importantly, as long as district-specific seasonal patterns in employment and the long-run and measurement error components of nightlight activity growth are orthogonal to the demonetization shock $z_{i, t}$, the cross-sectional approach above remains valid despite these challenges (see appendix B.2 for additional detail). These considerations all favor emphasis on the impact of demonetization as revealed by the cross-sectional patterns.

\subsection{Aggregate Implications of the Cross-Section}

To assess the implications of the cross-sectional patterns for the aggregate impact of demonetization, we start by cumulating the cross-sectional effects over districts. This calculation uses the cross-sectional coefficient to impute to each district the change in the outcome variable relative to if no change in money balances had occurred, i.e. $Z_{i, t}=1$, and then sums over districts. The calculation would exactly recover the national impact of the currency shortfall if each district were an isolated entity. The formula for the cumulated effect in 
month $t$ is:

$$
\frac{\sum_{i: Z_{i, t} \leq 1}\left(e^{\beta_{1, t} z_{i, t}}-1\right) Y_{i, \text { baseline }}}{\sum_{i} Y_{i, \text { baseline }}} \approx \frac{\beta_{1, t} \sum_{i: Z_{i, t} \leq 1} z_{i, t} Y_{i, \text { baseline }}}{\sum_{i} Y_{i, \text { baseline }}},
$$

where $Y_{i, \text { baseline }}$ denotes the level of the variable in the pre-demonetization period. Intuitively, the cumulated decline is approximated by the regression coefficient multiplied by a pre-treatment outcome-weighted average of the demonetization shock. Using the coefficients shown in columns (1) and (4) of table 6, for employment this calculation yields a decline of 3.3 p.p., while for nightlights this calculation yields a decline of 12.0 p.p., which translates into an output decline of 3.6 p.p. after applying the 0.3 elasticity advocated by Henderson, Storeygard, and Weil (2012). Appendix figure B.3 shows the counterfactual paths of employment and nightlight activity implied by these totals.

The preceding calculation assumes a log-linear relationship between the cash shortage and outcome variables. While the scatter plots shown above appear consistent with such linearity, we lack the power to test for a non-linearity or kink at small declines in cash because essentially all districts experienced a large decline in currency. Assuming instead a flat relationship (no effect of the cash shortage on outcomes) for cash declines of less than $10 \%$ would change the implied decline in employment to 3.0 p.p. and the decline in nightlights to 10.9 p.p. ${ }^{32}$

The next step is to relate the quantity defined in equation (19) to the actual national effect of demonetization. Two types of considerations arise. First, the impact of the currency shortage found in the cross-section may differ from the impact in the aggregate. In the context of the model in section 3, trade linkages across districts make the cumulated decline in output a lower bound for the true aggregate decline. The lower bound arises because of the tradeables sector; some of the demand shortfall in a local area gets exported to other areas through trade linkages. This logic closely relates to theoretical results presented in Nakamura and Steinsson (2014), Farhi and Werning (2016), and Chodorow-Reich (2019) in the context of estimation of cross-sectional fiscal multipliers. In the demonetization context the lower bound is especially sharp because national interest rates remained fixed and total government liabilities did not change. Moreover, the model accommodates arbitrary labor mobility without impacting the lower bound result because the downward wage constraint

\footnotetext{
${ }^{32}$ Alternatively, we can attempt to adjust the district-level shocks by the fraction of demonetized notes that had been used for storage by assuming constant chest velocity of notes not used for storage. Doing so implies slightly smaller but still statistically significant aggregated declines in employment and nightlight activity.
} 
binds in all areas. More generally, higher labor mobility at the local than the national level, which can make cross-sectional multipliers larger than the aggregate (Chodorow-Reich, 2019), cannot undo the lower bound in this case because our empirical labor market measure - the employment-to-population ratio - already removes the component of the employment change due to labor mobility. ${ }^{33}$

Applying the lower bound result to the cross-sectional estimates for employment and nightlights, we conclude that the cash shortage caused by demonetization generated a decline in national economic activity of roughly 3 p.p. or more in November and December 2016 relative to a no-demonetization counterfactual. ${ }^{34}$ Similarly, the effect on credit implies a 2 p.p. or more decline in 2016Q4. These effects dissipate over the few months. Is such a decline large? The magnitude of the peak effect on output is comparable to a roughly 200 basis point tightening of the monetary policy rate based on the median of estimates reviewed in Ramey (2016) of econometric studies of U.S. data. Moreover, it rejects the cashless limit wherein all that matters in the conduct of monetary policy is the interest rate. On the other hand, the output decline is an order of magnitude smaller than the decline in cash itself. This difference illustrates the Lucas (1976) critique in action - in response to a change in policy, agents endogenously adjust (changing $\kappa$ in our model) rather than passively obeying a pre-existing CIA constraint.

The second consideration in relating the cumulated cross-sectional results to the aggregate involves effects of demonetization beyond the decline in currency. For example, demonetization may have bolstered or curtailed confidence in the government or caused short-run supply disruptions as economic activity migrated from the informal to the formal sector. Our evidence speaks to the effect of the cash shortage caused by demonetization on cross-sectional and aggregate outcomes; it does not inform about other possible channels which apply only at the aggregate level or are orthogonal to the cash replacement shock. Abstracting from these other channels, the lower bound result for the impact of the cash shortage points to an absolute decline in economic activity at the end of 2016 not captured in official statistics. ${ }^{35}$

\footnotetext{
${ }^{33}$ More precisely, the cumulation of the employment results imposes fixed population. If in reality some workers moved from more-demonetized to less-demonetized regions, then the number in the text would understate the employment decline.

${ }^{34}$ The aggregated changes in ATM withdrawals, e-wallet transactions, and POS transactions from applying equation (19) are also all smaller than the actual aggregate changes. However, some special factors apply to these variables. Many ATMs temporarily went out of service to receive recalibration required to dispense the new notes, independent of cash availability. Increasing returns to scale of payments technologies, information network effects, and increased advertising all may have contributed to a common component of adoption of alternative payments technologies across areas.

${ }^{35}$ In the context of our model, aggregate economic activity must have declined if the wage constraint was
} 


\section{Conclusion}

Using geographic variation in the severity of demonetization, we have shown that a sharp, temporary decline in currency caused declines in ATM withdrawals, reduced economic activity, faster adoption of alternative payment technologies, and higher deposit and lower bank credit growth in Indian districts. These cross-sectional patterns reject monetary neutrality and the cashless limit in this episode.

While certainly exotic, demonetization offers lessons for other settings. For example, what economic costs would result from a country leaving the euro and having to print new national currency? Or, in a country such as Sweden that already largely uses electronic payment media, what would happen if the national payments network were to suffer an outage? Our results point to the possibility of substantial economic disruption in these events.

Finally, we focus in this paper on the near term impact of demonetization. Our identification strategy based on random shocks to the cross-section of districts best lends itself to near term analysis. There may be longer term advantages from demonetization that arise from improvements in tax collections and in a shift to savings in financial instruments and non-cash payment mechanisms. Evaluating these long-term consequences requires waiting for more data and an empirical strategy suited to the study of longer term effects.

binding. If trend growth in India was $1.5 \%$ per quarter (6\% per year), then our estimates imply an absolute decline in economic activity of about $0.5 \%$ (2\% annualized) in 2016Q4 from the previous quarter. This follows from the $3 \%$ decline in November and December and no impact in the pre-demonetization month of October. 


\section{References}

Aggarwal, N., and S. Narayanan (2017): "Impact of India's Demonetization on Domestic Agricultural Markets," .

Agrawal, S. (2018): "Black Economy and Demonetisation," .

Alvarez, F., And F. Lippi (2009): "Financial Innovation and the Transactions Demand for Cash," Econometrica, 77(2), 363-402.

Banerjee, A., E. Breza, A. G. Chandrasekhar, and B. Golub (2018): "When Less is More: Experimental Evidence on Information Delivery During India's Demonetization," Working Paper 24679, National Bureau of Economic Research.

BanerJee, A., And N. Kala (2017): “The Economic and Political Consequences of India's Demonetization," .

Bell, R., And D. McCaffrey (2002): "Bias Reduction in Standard Errors for Linear Regression with Multi-Stage Samples," Survey Methodology, 28, 169-181.

CEA (2017): Economic Survey 2016-17 Volume Ichap. Economic Outlook and Policy Challenges, pp. 1-37. Ministry of Finance.

Chodorow-Reich, G. (2019): "Geographic Cross-Sectional Fiscal Multipliers: What Have We Learned?," American Economic Journal: Economic Policy, 11(2), 1-36.

Crouzet, N., A. Gupta, and F. Mezzanotti (2019): "Shocks and Technology Adoption: Evidence from Electronic Payment Systems," .

CSO (2015): "Changes in Methodology and Data Sources in the New Series of National Accounts," Discussion paper, Central Statistics Office, Government of India.

- (2018): "First Revised Estimates Of National Income, Consumption Expenditure, Saving And Capital Formation For 2016-17," Discussion paper, Central Statistics Office, Government of India.

Elvidge, C., K. Baugh, M. Zhizhin, F. Hsu, and T. Ghosh (2017): "VIIRS Nighttime Lights," International Journal of Remote Sensing, 38(21), 5860-5879.

FArhi, E., AND I. Werning (2016): "Fiscal Multipliers," Handbook of Macroeconomics, 2, $2417-2492$. 
Goldman Sachs (2017): "Trackin' All Over the World - Our New Global CAI," Discussion paper, Goldman Economics Analyst.

Henderson, J. V., A. Storeygard, and D. N. Weil (2012): "Measuring Economic Growth from Outer Space," American Economic Review, 102(2), 994-1028.

ILO (2018): "Women and Men in the Informal Economy: A Statistical Picture," Discussion paper, International Labour Office.

Imbens, G. W., And M. Kolesár (2016): "Robust Standard Errors in Small Samples: Some Practical Advice," The Review of Economics and Statistics, 98(4), 701-712.

Kaur, S. (forthcoming): "Nominal Wage Rigidity in Village Labor Markets," American Economic Review.

Kocherlakota, N. R. (1998): "Money Is Memory," Journal of Economic Theory, 81(2), $232-251$.

Krishnan, D., and S. Siegel (2017): "Survey of the Effects of Demonetisation on 28 Slum Neighborhoods of Mumbai," Economic \& Political Weekly, 52(3).

Lagos, R., And S. Zhang (2018): "On Money as a Medium of Exchange in Near-Cashless Credit Economies," .

LuCAS, R. E. (1976): "Econometric policy evaluation: A critique," Carnegie-Rochester Conference Series on Public Policy, 1, $19-46$.

(1982): "Interest rates and currency prices in a two-country world," Journal of Monetary Economics, 10(3), 335 - 359.

Lucas, R. E., And N. L. Stokey (1987): "Money and Interest in a Cash-in-Advance Economy," Econometrica, 55(3), 491-513.

Modi, N. (2016): "Address to the Nation," Address to the nation by Prime Minister Narendra Modi, November 8, 2016.

Nakamura, E., And J. Steinsson (2014): "Fiscal Stimulus in a Monetary Union: Evidence from US Regions," American Economic Review, 104(3), 753-92.

Nakamura, E., And J. Steinsson (2018): "Identification in Macroeconomics," Journal of Economic Perspectives, 32(3), 59-86. 
Ramey, V. (2016): "Chapter 2 - Macroeconomic Shocks and Their Propagation," vol. 2 of Handbook of Macroeconomics, pp. 71 - 162. Elsevier.

RBI (2016): "DCM (Plg) No.1226/10.27.00/2016-17," .

RBI (2017a): “Annual Report 2016-17,” Discussion paper, Reserve Bank of India. (2017b): "Macroeconomic Impact of Demonetisation - A Preliminary Assessment," Discussion paper, Reserve Bank of India.

_ (2018): “Annual Report 2017-18," Discussion paper, Reserve Bank of India.

Rogoff, K. S. (2016): The Curse of Cash: How Large-Denomination Bills Aid Crime and Tax Evasion and Constrain Monetary Policy. Princeton University Press.

Schmitt-Grohé, S., And M. Uribe (2016): "Downward Nominal Wage Rigidity, Currency Pegs, and Involuntary Unemployment," Journal of Political Economy, 124(5), 14661514.

Solon, G., S. J. Haider, and J. M. Wooldridge (2015): "What Are We Weighting For?," Journal of Human Resources, 50(2), 301-316.

Svensson, L. E. O. (1985): "Money and Asset Prices in a Cash-in-Advance Economy," Journal of Political Economy, 93(5), 919-944.

VELDE, F. R. (2009): "Chronicle of a Deflation Unforetold," Journal of Political Economy, $117(4), 591-634$.

Williamson, S., And R. Wright (2010): "New Monetarist Economics: Methods," Research Department Staff Report 442, Federal Reserve Bank of Minneapolis.

Woodford, M. (2003): Interest and Prices: Foundations of a Theory of Monetary Policy. Princeton University Press.

World Bank (2017): "Growth Out of The Blue," South Asia Economic Focus. 


\title{
Cash and the Economy: \\ Evidence from India's Demonetization
}

\author{
Online Appendix
}

\author{
Gabriel Chodorow-Reich Gita Gopinath \\ Prachi Mishra Abhinav Narayanan
}

\section{A Model Proofs}

We begin by stating all of the first order conditions for the household:

$$
\begin{array}{rlrl}
C_{i, t}: & U^{\prime}\left(C_{i, t}\right) & =\left(\lambda_{i, t}+\kappa \theta_{i, t}\right) P_{i, t}, \\
M_{i, t}: & \lambda_{i, t}\left(1+\tau^{\prime}\left(\eta_{i, t}\right)\right) & =\beta\left[\lambda_{i t+1}+\theta_{i t+1}\right], \\
D_{i, t}: & \lambda_{i, t} & =\beta R_{t} \lambda_{i t+1}, \\
C_{i, t}^{N}: & P_{i, t}^{N} C_{i, t}^{N}=(1-\alpha) P_{i, t} C_{i, t} \\
C_{i, t}^{T}: & P_{t}^{T} C_{i, t}^{T}=\alpha P_{i, t} C_{i, t} \\
C_{i, t}^{T}(\omega): & C_{i, t}^{T}(\omega)=\left(\frac{P_{t}^{T}(\omega)}{P_{t}^{T}}\right)^{-\sigma} C_{i, t}^{T}
\end{array}
$$

along with the complementary slackness conditions,

$$
\begin{array}{r}
\theta_{i, t} \cdot\left(\kappa P_{i, t} C_{i, t}-M_{i t-1}-T_{i, t}^{M}\right)=0, \\
h^{\prime}\left(f_{i, t}\right)=-\theta_{i, t} \kappa^{\prime}\left(f_{i, t}\right) P_{i, t} C_{i, t},
\end{array}
$$

where $\lambda_{i, t}$ is the Lagrange multiplier on the budget constraint and $\theta_{i, t}$ is the Lagrange multiplier on the CIA constraint. We use the functional form $\tau\left(\eta_{i, t}\right)=\frac{\bar{\tau}}{e^{\nu \eta_{i, t}}}$ where $0<\nu<1$.

\section{Pre-Demonetization Steady State}

The economy in period -1 is in a steady state where because of tax evasion incentives the CIA does not bind, $M_{-1}>\bar{\kappa} P_{-1} C_{-1}$. This requires that $\bar{\kappa}\left(1+\varphi\left(\frac{1}{\beta}-1\right)\right)<\frac{1}{\nu} \ln \left(\frac{\nu \bar{\tau}}{1-\beta}\right)$, that is, that the tax rate $\bar{\tau}$ is sufficiently high relative to the interest rate and to the fraction of 
spending that needs to be undertaken in cash absent any adoption of financing technology $\bar{\kappa}$. This assumption reflects the argument made by the Indian government that an important fraction of pre-demonetization cash was 'black money' held for tax evasion purposes.

\section{Proposition A.1 Pre-demonetization steady state}

In period -1 all regions are in a symmetric zero inflation steady state with $M^{s}=M_{-1}$, and

1. The economy is in full employment:

$$
N_{-1}=\bar{N}, \quad Y_{-1}^{T}=N_{-1}^{T}=\alpha \bar{N}, \quad Y_{-1}^{N}=N_{-1}^{N}=(1-\alpha) \bar{N}
$$

2. Real money balances are increasing in the level of consumption $C$ and in the labor income tax $\bar{\tau}$ and decreasing in the interest rate $R_{-1}=1 / \beta$ :

$$
\frac{M_{-1}}{P_{-1}}=\frac{\eta_{-1} C_{-1}}{\left(1+\varphi\left(R_{-1}-1\right)\right)}, \quad \eta_{-1}=\frac{1}{\nu} \ln \left(\frac{\nu \bar{\tau}}{1-\left(1 / R_{-1}\right)}\right)
$$

3. Nominal wages and prices are given by:

$$
W_{-1}=\frac{M_{-1}}{\bar{N} \eta_{-1}}, \quad P_{-1}^{T}=P_{-1}^{N}=\left(1+\varphi\left(\beta^{-1}-1\right)\right) \frac{M_{-1}}{\bar{N} \eta_{-1}}
$$

With a constant level of money supply in the economy, the wage friction does not bind and the economy is in full employment with a fraction $\alpha$ of labor employed in the traded sector and $(1-\alpha)$ in the non-traded sector.

\section{Proof}

Begin by assuming $\theta_{-1}=0$. We will later derive the parameter restrictions under which this is the case. From the F.O.C. for cash in the steady state, we have that:

$$
\eta_{-1}=\frac{1}{\nu} \log \left(\frac{\nu \bar{\tau}}{1-\beta}\right)
$$

From the definition of $\eta$ it the follows that:

$$
W_{-1}=\frac{M_{-1}}{N_{-1} \eta_{-1}}
$$


From the F.O.C. for consumption in a zero inflation steady state it follows that real consumption is constant which implies that labor is constant. This further implies that wages are constant so the downward nominal rigidity is not binding and the economy is in full employment, i.e. $N_{-1}=\bar{N}$

Now, again using the definition of $\eta_{-1}$ and the firms optimality conditions we have:

$$
W_{-1}=\frac{M_{-1}}{\bar{N} \eta_{-1}}, \quad P_{-1}^{T}=P_{-1}^{N}=\left(1+\varphi\left(\beta^{-1}-1\right)\right) \frac{M_{-1}}{\bar{N} \eta_{-1}}
$$

As prices for both types of goods are the same, using the F.O.C. for tradable and nontradable goods we have that:

$$
\frac{C_{-1}^{N}}{C_{-1}^{T}}=\frac{1-\alpha}{\alpha}
$$

Applying market clearing conditions, $C_{-1}^{T}=N_{-1}^{T}, C_{-1}^{N}=N_{-1}^{N}, N_{-1}^{N}+N_{-1}^{T}=\bar{N}$ and rearranging yields:

$$
N_{-1}^{N}=(1-\alpha) \bar{N}, \quad N_{-1}^{T}=\alpha \bar{N}
$$

From where point 1 follows immediately. For the remaining part of point 2 take the optimal price of the non-tradable good producer, multiply both sides by $(1-\alpha) \bar{N}$ and use the market clearing condition for this good:

$$
P_{-1}^{N} C_{-1}^{N}=(1-\alpha)\left(1+\varphi\left(\beta^{-1}-1\right)\right) \frac{M_{-1}}{\eta_{-1}}
$$

Using the bundling condition for non-tradable goods and rearranging yields point 2 :

$$
\frac{M_{-1}}{P_{-1}}=\frac{\eta_{-1} C_{-1}}{1+\varphi\left(\beta^{-1}-1\right)}
$$

It is only left to show that indeed $\theta_{-1}=0$. We may rearrange this last expression as:

$$
P_{-1} C_{-1}=\left(1+\varphi\left(\beta^{-1}-1\right)\right) \frac{M_{-1}}{\eta_{-1}}
$$

Now the cash-in-advance constraint being slack can equivalently be stated as:

$$
\bar{\kappa}\left(1+\varphi\left(\beta^{-1}-1\right)\right)<\eta_{-1}
$$

And substituting the value for $\eta_{-1}$ : 


$$
\bar{\kappa}\left(1+\varphi\left(\beta^{-1}-1\right)\right)<\frac{1}{\nu} \log \left(\frac{\nu \bar{\tau}}{1-\beta}\right)
$$

A restriction on parameters that we impose.

\section{Proof of proposition 1}

Start by assuming that both the cash-in-advance constraint and the downward nominal rigidity are binding. Now using the cash-in-advance constraint, the bundling condition for the non-tradable good, and the market clearing condition for this good we find that:

$$
\begin{array}{r}
\bar{\kappa} \frac{P_{0}^{N} N_{0}^{N}}{1-\alpha}=M_{0} \\
\Leftrightarrow N_{0}^{N}=\frac{(1-\alpha) M_{0}}{\bar{\kappa} P_{0}^{N}}
\end{array}
$$

Using the optimality condition for the producer of the non-tradable good, the nominal rigidity, and the fact that interest rates remain constant, we can substitute for the price of the non-tradable good and obtain:

$$
\begin{aligned}
N_{0}^{N} & =\frac{M_{0}}{\gamma M_{-1}} \cdot \frac{\eta_{-1}}{\kappa\left(1+\varphi\left(\beta^{-1}-1\right)\right)}(1-\alpha) \bar{N} \\
& =\frac{Z}{\gamma} \cdot \frac{\eta_{-1}}{\bar{\kappa}\left(1+\varphi\left(\beta^{-1}-1\right)\right)}(1-\alpha) \bar{N}
\end{aligned}
$$

And through the same procedure:

$$
N_{0}^{T}=\frac{Z}{\gamma} \cdot \frac{\eta_{-1}}{\bar{\kappa}\left(1+\varphi\left(\beta^{-1}-1\right)\right)} \alpha \bar{N}
$$

Finally:

$$
\frac{Y_{0}}{Y_{-1}}=\frac{Z}{\gamma} \cdot \frac{\eta_{-1}}{\bar{\kappa}\left(1+\varphi\left(\beta^{-1}-1\right)\right)}
$$

which proves point 1. Aggregate price level is given by:

$$
P_{0}=\frac{\left(1+\varphi\left(\beta^{-1}-1\right)\right) \gamma W_{-1}}{\alpha^{\alpha}(1-\alpha)^{1-\alpha}}
$$


Now, real lending to firms is given by:

$$
\frac{B_{0}^{f}}{P_{0}}=\frac{\alpha^{\alpha}(1-\alpha)^{1-\alpha} \varphi N_{0}}{1+\varphi\left(\beta^{-1}-1\right)}
$$

Similarly:

$$
\frac{B_{-1}^{f}}{P_{-1}}=\frac{\alpha^{\alpha}(1-\alpha)^{1-\alpha} \varphi \bar{N}}{1+\varphi\left(\beta^{-1}-1\right)}
$$

Since $N_{0}<\bar{N}$,

$$
\frac{B_{0}^{f}}{P_{0}}<\frac{B_{-1}^{f}}{P_{-1}}
$$

It is only left then to show that demonetization makes the downward nominal rigidity and the cash-in-advance constraint binding. Multiplying both sides of the optimality condition of non-tradable goods producer by $C_{i, 0}^{N}=N_{0}^{N}$ yields:

$$
P_{0}^{N} C_{0}^{N}=\left(1+\varphi\left(\beta^{-1}-1\right)\right) N_{0}^{N} W_{0}^{N} .
$$

Now, using the cash-in-advance constraint and the bundling condition for non-tradable goods we find that:

$$
(1-\alpha) \frac{M_{i, 0}}{\bar{\kappa}}=\left(1+\varphi\left(\beta^{-1}-1\right)\right) N_{0}^{N} W_{0}
$$

Since demonetization is homogeneous, regional trade balances remain at zero so we may use the same procedure for tradeable goods to find that:

$$
\alpha \frac{M_{0}}{\bar{\kappa}}=\left(1+\varphi\left(\beta^{-1}-1\right)\right) N_{0}^{T} W_{0}
$$

Adding these two up, using labor markets' clearing condition and rearranging yields:

$$
W_{0}=\frac{M_{0}}{\bar{\kappa}\left(1+\varphi\left(\beta^{-1}-1\right)\right) N_{0}}
$$

Now we derive the condition under which if $N_{0}=\bar{N}$ then $W_{0}<\gamma W_{-1}$ :

$$
\begin{aligned}
& \frac{M_{0}}{\bar{\kappa}\left(1+\varphi\left(\beta^{-1}-1\right)\right) \bar{N}}<\frac{\gamma M_{-1}}{\bar{N} \eta_{-1}} \\
\Leftrightarrow & Z \frac{\eta_{-1}}{\bar{\kappa}\left(1+\varphi\left(\beta^{-1}-1\right)\right)}<\gamma
\end{aligned}
$$

Under this conditions $N_{0}<\bar{N}$ and $W_{0}=\gamma W_{-1}$ as in point 3. Finally, for the cash-in-advance 
constraint to hold, we have that:

$$
\begin{array}{r}
\frac{\kappa}{M_{0}}=\lambda_{0}+\bar{\kappa} \theta_{0} \\
\lambda_{0}\left(1+\tau^{\prime}\left(\eta_{i, 0}\right)\right)=\beta \lambda_{1}
\end{array}
$$

Notice that we have used the fact that the cash-in-advance constraint is not expected to bind in $t>0$. From these two equations it follows that:

$$
\theta_{0}=\frac{1}{M_{0}}-\frac{\beta \lambda_{i, 1}}{\bar{\kappa}\left(1+\tau^{\prime}\left(\eta_{0}\right)\right)}
$$

From the problem at $t=1$ we have that:

$$
\lambda_{1}=\frac{\eta_{1}}{\left(1+\varphi\left(\beta^{-1}-1\right)\right) M_{1}}
$$

Now, rearranging, we find that $\theta_{0}>0$ may equivalently be written as:

$$
\frac{M_{1}}{M_{0}}>\frac{\beta \eta_{1}}{\bar{\kappa}\left(1+\tau^{\prime}\left(\eta_{0}\right)\right)\left(1+\varphi\left(\beta^{-1}-1\right)\right)}
$$

Then, given this parameter restrictions, the cash-in-advance constraint is binding at $t=0$.

\section{Proof of proposition 2}

We will again start by assuming that the downward nominal rigidity is binding and then show conditions under which this is the case. We now have that in every region the optimality condition for the producers of the non-tradable good is given by:

$$
\begin{aligned}
P_{i, 0} & =\left(1+\varphi\left(\beta^{-1}-1\right)\right) \gamma W_{-1} \\
& =\left(1+\varphi\left(\beta^{-1}-1\right)\right) \gamma \frac{M_{-1}}{\eta_{-1} \bar{N}}
\end{aligned}
$$

Multiplying both sides by $C_{i, 0}=N_{i, 0}^{N}$, using the cash-in-advance constraint, and the bundling condition for the non-tradable good yields:

$$
(1-\alpha) \frac{M_{i, 0}}{\bar{\kappa}}=\left(1+\varphi\left(\beta^{-1}-1\right)\right) \gamma \frac{M_{-1}}{\eta_{-1} \bar{N}} N_{i, 0}^{N}
$$


Rearranging and using the definition of $Z_{i}$ :

$$
N_{i, 0}^{N}=\frac{(1-\alpha) Z_{i}}{\gamma} \frac{\eta_{-1} \bar{N}}{\bar{\kappa}\left(1+\varphi\left(\beta^{-1}-1\right)\right)}
$$

As wages are constant across regions, so are the prices for tradeable varieties which implies that $C_{j, 0}^{T}(\omega)=C_{j, 0}^{T}$. Now, using the tradable good producers' optimality condition, the cashin-advance constraint, and the bundling condition for tradable goods, it is possible to find that:

$$
\frac{\alpha}{\bar{\kappa}} Z_{j, 0}=\frac{\left(1+\varphi\left(\beta^{-1}-1\right) \gamma\right)}{\bar{N} \eta_{-1}} C_{j, 0}^{T}(i)
$$

Integrating over $j$ in both sides and using the market clearing condition for tradable variety $i$ yields:

$$
\begin{aligned}
\frac{\alpha}{\bar{\kappa}} Z & =\frac{\left(1+\varphi\left(\beta^{-1}-1\right)\right) \gamma}{\bar{N} \eta_{-1}} N_{i, 0}^{T} \\
\Leftrightarrow N_{i, 0}^{T} & =\frac{\alpha Z}{\gamma} \frac{\eta_{-1} \bar{N}}{\bar{\kappa}\left(1+\varphi\left(\beta^{-1}-1\right)\right)}
\end{aligned}
$$

Given these values for $N_{i, 0}^{T}$ and $N_{i, 0}^{N}$, and the production functions, point 1 in the proposition follows.

Point 2 follows directly from the fact that $B_{i, 0}^{f}=\varphi \gamma W_{-1} N_{i, 0}$ and $P_{0}=\alpha^{\alpha}(1-\alpha)^{1-\alpha}(1+$ $\left.\varphi\left(\beta^{-1}-1\right)\right) \gamma W_{-1}$. It is only left to prove that $W_{i, 0}=\gamma W_{-1}$, i.e. the downward nominal rigidity is binding. The complementary slackness condition is given by:

$$
\left(\bar{N}-N_{i, 0}\right)\left(W_{i, 0}-\gamma W_{i,-1}\right)=0
$$

From point 1 we have that if:

$$
\gamma>(\alpha Z+(1-\alpha) \tilde{Z}) \frac{\eta_{-1}}{\bar{\kappa}\left(1+\varphi\left(\beta^{-1}-1\right)\right)}
$$

Where $\tilde{Z}=\max _{j} Z_{j}$, then $W_{i, 0}=\gamma W_{-1}$ in every region $i$. With heterogenous money shocks regions with lower money replacement rates enter period 1 with higher financial wealth. The evolution of savings is given by $D_{j, 1}-D_{0}=\left(Y_{0}^{T}(\omega)-C_{j, 0}^{T}(\omega)\right)+\left(R_{0}-1\right) D_{0}$, where $\left(Y_{0}^{T}(\omega)-C_{j, 0}^{T}(\omega)\right)$ is the trade balance and $\left(R_{0}-1\right) D_{0}$ the interest earning on deposits from the previous period. ${ }^{1}$ Because $Y_{0}^{T}(\omega)$ depends on aggregate demand and is the same across

\footnotetext{
${ }^{1}$ This is assuming that government lump-sum transfers in each region exactly equal the labor income tax
} 
regions, but $\left.C_{j, 0}^{T}(\omega)\right)$ is increasing in $Z$, regions with lower $Z$ run trade balance surpluses in period 0 . This means that starting in period 1 low $Z$ regions have permanently higher wealth, and higher consumption by the amount of the interest earning on their deposits $\left(\frac{1}{\beta}-1\right) D_{j, 1}$. An alternative, would be to allow the government to use lump-sum taxes to undo the dispersion in wealth in period 1. This would have no meaningful impact on the period 0 solution.

\section{Numerical Illustration with Endogenous $\kappa$}

We use the following functional forms: $\kappa(f)=\bar{\kappa} e^{-\zeta f}$ and $h(f)=\frac{a}{2} f^{2}$. Now it follows that $\theta_{i, 0}=\frac{a f_{i, 0}}{\zeta M_{i, 0}}$. Further:

$$
\begin{gathered}
\left(\frac{a f_{i, 0}-\zeta}{\zeta}\right) \kappa\left(f_{i, 0}\right)\left(1+\tau^{\prime}\left(\eta_{i, 0}\right)\right)+\beta \lambda_{i, 1} M_{i, 0}=0 \\
\eta_{i, 0}=\frac{Z_{i}}{\alpha \bar{Z}+(1-\alpha) Z_{i}} \kappa\left(f_{i, 0}\right)\left(1+\varphi\left(\beta^{-1}-1\right)\right.
\end{gathered}
$$

By substituting the second equation of this set in the first one we arrive at a single equation in $f_{i, 0}$. We then have that, $f_{i, 0}=\Psi\left(\mathcal{I}, Z_{i}\right)$ where $\mathcal{I}$ satisfies $\mathcal{I}=\int \psi\left(\mathcal{I}, Z_{j}\right) d j$. For the numerical solution we consider a discrete distribution for $Z_{i}$ with finite support $\left\{Z_{1}, \ldots, Z_{S}\right\}$ and $\mathbb{P}\left(Z<Z_{s}\right)=w_{s}$, of course, $w_{S}=1$. Notice that in this case $\mathcal{I}=\sum_{s=1}^{S} \frac{Z_{s}}{\kappa\left(f_{s, 0}\right)} \Delta w_{s}$. We employ the parameter values shown in table A.1.

paid plus region specific money infusion, that is there is no redistribution. 


\begin{tabular}{cc}
\hline Parameter & Value \\
\hline \hline$a$ & 0.01 \\
$\alpha$ & 0.4 \\
$\bar{\kappa}$ & 1 \\
$\bar{\tau}$ & 0.2 \\
$\beta$ & 0.98 \\
$\gamma$ & 1 \\
$M_{-1}$ & 1 \\
$M_{1}$ & 1 \\
$\bar{N}$ & 1 \\
$\nu$ & 2.5 \\
$\varphi$ & 0.9 \\
$\zeta$ & 10 \\
\hline
\end{tabular}

\begin{tabular}{ccc}
\hline$s$ & $Z_{s}$ & $w_{s}$ \\
\hline \hline 1 & 0.0431 & 0.01 \\
2 & 0.089 & 0.05 \\
3 & 0.126 & 0.1 \\
4 & 0.21 & 0.25 \\
5 & 0.307 & 0.5 \\
6 & 0.464 & 0.75 \\
7 & 0.636 & 1
\end{tabular}

Table A.1: Parameter values 
Figure B.1: Aggregate New Notes

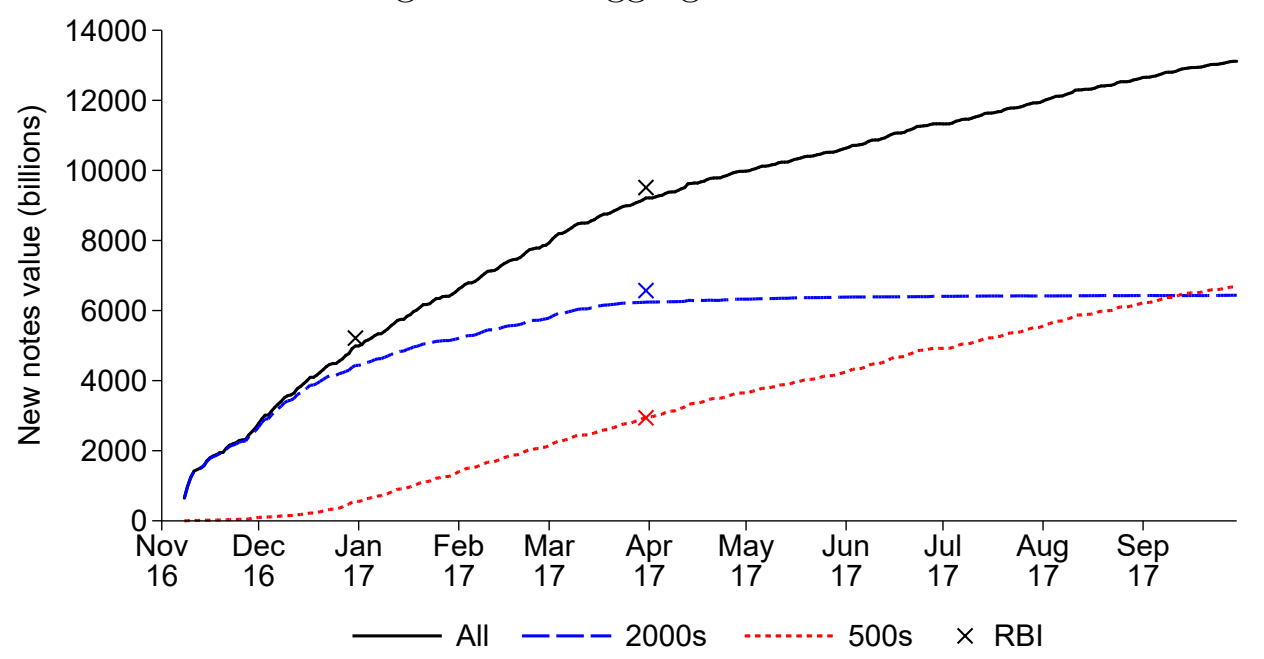

Notes: The figure plots the aggregate value of new 500 and 2000 notes using our data and the definitions given in equations (11) and (12). For comparsion, the xs show the value of total new notes as stated in RBI (2017a, p. 124 and table VIII.1).

\section{B Data Appendix}

\section{B.1 Data Benchmark}

The currency chest data from the RBI are confidential and not publicly available. Figure B.1 plots the aggregate value of new notes in our data over time, using the definitions given in equation (11) and equation (12). For comparison, the xs show the value of new notes as stated in RBI (2017a). Our measures track the RBI official reporting extremely closely in both levels and differences.

\section{B.2 Nightlights versus Electricity}

Nightlight activity correlates with real economic activity because it reflects nighttime electricity use. Figure B.2 compares aggregate nightlight activity and total electricity use in the quarters surrounding demonetization. Both variables fall in the quarter of demonetization. However, only nightlight activity rebounds sharply in 2017Q1, demonstrating that nightlight activity and electricity use can sometimes diverge.

We now discuss why nightlight activity remains a valid measure for our cross-sectional analysis despite the difficulties that arise in using aggregate nightlight activity to infer the impact of demonetization. Let $Y_{i, t}$ denote total nightlight activity in district $i$ in quarter $t$. 
Figure B.2: Aggregate Nightlight Activity and Electricity Use Seasonally Adjusted

Not Seasonally Adjusted
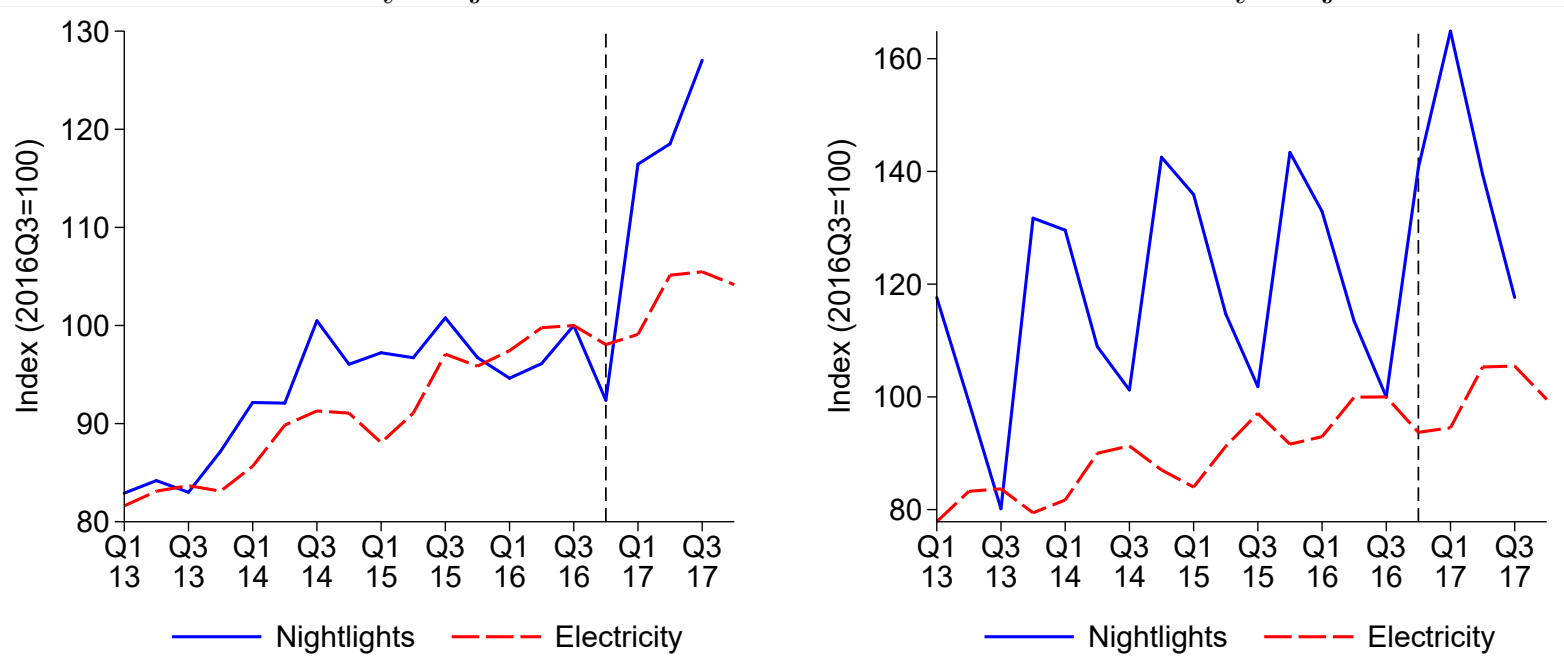

Notes: Seasonal adjustment of nightlight activity is done at the district level as described in the main text of the paper. Seasonal adjustment of electricity is done at the aggregate level by regressing electricity on four quarterly categorical variables and a linear time-trend.

We decompose nightlight activity into a number of factors:

$$
Y_{i, t}=M_{i, t} C_{i, t} U_{i, t}
$$

where $C_{i, t}$ denotes electric capacity and reflects long-run factors such as the degree of electrification, $U_{i, t}$ denotes utilization, and $M_{i, t}$ denotes the component of nightlight activity unrelated to economic activity (e.g. from not removing stray light or changing seasonal patterns due to the satellite collection). For simplicity, we will refer to the component $M_{i, t}$ as measurement error. Let $\Delta$ denote the difference operator, a lower case variable the log of the uppercase variable, and $Y_{t}=\sum_{i} Y_{i, t}$ aggregate nightlight activity. Then it is clear that $\Delta y_{t}$ could reflect growth in the high frequency component related to economic activity, $\Delta u_{t}$, the long-run component $\Delta c_{t}$, or measurement error $\Delta m_{t}$.

Importantly, under our maintained assumption that severity of demonetization was as good as randomly assigned, cross-sectional differences in nightlight activity growth isolate the effect of demonetization on the high frequency business cycle component. Specifically, we have that $z_{i, t}$ is uncorrelated with $\Delta m_{i, t}$ and $\Delta c_{i, t}$. Therefore, the coefficient from a regression of $\Delta y_{i, t}$ on $z_{i, t}$ is equal to the coefficient from a regression of $\Delta u_{i, t}$ on $z_{i, t}$; the regression captures only the cross-sectional effect of demonetization on the component related to high frequency economic activity. 
Table B.1: Nightlight Growth, Electricity Growth, and Demonetization Severity, 2016Q4

\begin{tabular}{|c|c|c|c|c|}
\hline \multirow{3}{*}{ Aggregation: } & \multicolumn{4}{|c|}{ Dep. var.: log change in nightlight intensity } \\
\hline & \multirow{2}{*}{$\begin{array}{c}\text { District } \\
(1)\end{array}$} & \multicolumn{3}{|c|}{ State } \\
\hline & & $(2)$ & $(3)$ & $(4)$ \\
\hline \multirow[t]{2}{*}{ Demonetization shock } & $1.20^{* *}$ & $0.87^{+}$ & & 0.01 \\
\hline & $(0.37)$ & $(0.41)$ & & $(0.47)$ \\
\hline \multirow[t]{2}{*}{ Log change in electricity use } & & & $3.38^{* *}$ & $3.38^{* *}$ \\
\hline & & & $(0.83)$ & $(1.03)$ \\
\hline Weight & None & Districts & Districts & Districts \\
\hline$R^{2}$ & 0.11 & 0.11 & 0.35 & 0.35 \\
\hline Observations & 473 & 33 & 33 & 33 \\
\hline
\end{tabular}

Notes: The dependent variable is the log point change in nightlights from 2016Q3 to 2016Q4 multiplied by 10. Column (1) reproduces the baseline result at the district level. Observations in columns (2)-(4) are collapsed to the state level and the regression is weighted by the number of districts in each state. Standard errors in parentheses. ${ }^{* *},{ }^{*},+$ denote significance at the 1,5 , or 10 percent level.

Finally, we use cross-sectional data on electricity use to validate the cross-sectional nightlight specification in the quarter of demonetization. Quarterly data on electricity use by district do not exist. Instead, we use state-level data on electricity use to show that demonetization affects nightlight intensity because demonetization affects electricity consumption. Table B.1 summarizes the results. Column (1) reproduces the baseline coefficient from the cross-district regression in 2016Q4 of nightlight growth on the log of the demonetization shock, $z$. Column (2) reports the same regression specification but after collapsing the data to the state level. To make the specification comparable to the district-level specification, we weight the regression by the number of districts in each state. The table shows a similar magnitude of response when using cross-state variation. Column (3) regresses nightlight growth on the growth rate of electricity use. The two variables are strongly correlated with each other. Finally, column (4) estimates a horse-race regression. Controlling for electricity growth makes the coefficient on demonetization essentially zero. This is exactly what should happen if nightlight growth is related to demonetization only because electricity consumption is related to demonetization. Thus, the effect of demonetization on nightlight use in the cross-state regression goes entirely through its effect on electricity use. 
Table B.2: Main Results with Alternative Measure of $Z_{i, t}$

\begin{tabular}{lccccc}
\hline \hline Dep. var. & \multicolumn{2}{c}{ Baseline } & & \multicolumn{2}{c}{ Large note share=0.87 } \\
\cline { 2 - 3 } \cline { 5 - 6 } & $\beta_{1, t}$ & s.e. & & $\beta_{1, t}$ & s.e. \\
\hline ATM withdrawals & $3.04^{* *}$ & 0.85 & & $3.37^{* *}$ & 1.09 \\
Employment & $0.34^{* *}$ & 0.09 & & $0.41^{* *}$ & 0.09 \\
Nightlights & $1.20^{* *}$ & 0.37 & & $1.28^{*}$ & 0.45 \\
E-Wallet & $-2.78^{* *}$ & 0.53 & & $-3.18^{* *}$ & 0.69 \\
POS & $-3.46^{*}$ & 1.31 & & $-4.04^{*}$ & 1.54 \\
Deposits & $-0.21^{*}$ & 0.09 & & $-0.25^{*}$ & 0.10 \\
Bank credit & $0.20^{* *}$ & 0.05 & & $0.23^{* *}$ & 0.06 \\
\hline \hline
\end{tabular}

Notes: The left panel reproduces the coefficients without controls in tables 5 to 8 . The right panel reports the coefficients and standard errors based on a measure of the demonetization shock $z_{i, t}$ which assumes demonetized notes were $87 \%$ of pre-demonetization currency everywhere. Standard errors clustered by state using the "LZ2" bias-reduction modification suggested by Imbens and Kolesár (2016). ${ }^{* *},{ }^{*},{ }^{+}$denote significance at the 1, 5, or 10 percent level based on a t-distribution with degrees of freedom for the currency replacement variable shown in the row "Treatment BM df".

\section{B.3 Restricting Variation Due to Demonetized Note Share}

Table B.2 reports our main results using an alternative measure of the demonetization shock. The left panel reproduces the coefficients without controls in tables 5 to 8 . The right panel reports the coefficients and standard errors based on a measure of the demonetization shock $Z_{i, t}$ which assumes demonetized notes were $87 \%$ of pre-demonetization currency everywhere.

\section{B.4 Heterogeneous Treatment Effects}

This appendix explores heterogeneous treatment effects. Specifically, for a variable $I_{i}$, we first normalize the variable to have zero mean and unit variance in the regression sample and then include both the level and the interaction of the normalized variable in the regression. Thus, the coefficient on the interaction term has the interpretation of the additional effect of the severity of demonetization for a district one standard deviation above the mean of the interacted variable. We consider two proxies for financial sophistication and urbanization: GDP per capita and population density. Neither interacts in an economically or statistically significant manner with the severity of demonetization. 
Table B.3: Interaction with GDP per Capita

\begin{tabular}{|c|c|c|c|c|c|c|c|}
\hline \multirow[t]{2}{*}{ Dep. var. } & ATM & Nightligh & Emp. & $\begin{array}{c}\text { E- } \\
\text { wallet }\end{array}$ & POS & Deposits & Credit \\
\hline & (1) & (2) & (3) & (4) & (5) & (6) & (7) \\
\hline$z_{i, t}$ & $\begin{array}{c}3.09^{* *} \\
(0.98)\end{array}$ & $\begin{array}{l}1.16^{* *} \\
(0.27)\end{array}$ & $\begin{array}{c}0.36^{* *} \\
(0.08)\end{array}$ & $\begin{array}{c}-2.94^{* *} \\
(0.61)\end{array}$ & $\begin{array}{r}-4.19^{*} \\
(1.42)\end{array}$ & $\begin{array}{c}-0.30^{* *} \\
(0.08)\end{array}$ & $\begin{array}{c}0.22^{* *} \\
(0.05)\end{array}$ \\
\hline Interaction & $\begin{array}{c}0.22 \\
(0.48)\end{array}$ & $\begin{array}{c}0.22 \\
(0.25)\end{array}$ & $\begin{array}{c}0.12 \\
(0.12)\end{array}$ & $\begin{array}{c}-0.13 \\
(0.49)\end{array}$ & $\begin{array}{c}-1.59 \\
(0.98)\end{array}$ & $\begin{array}{c}-0.12 \\
(0.07)\end{array}$ & $\begin{array}{c}-0.03 \\
(0.07)\end{array}$ \\
\hline$z_{i, t} \times$ Interaction & $\begin{array}{c}0.09 \\
(0.46)\end{array}$ & $\begin{array}{c}0.19 \\
(0.20)\end{array}$ & $\begin{array}{c}0.08 \\
(0.12)\end{array}$ & $\begin{array}{c}0.17 \\
(0.46)\end{array}$ & $\begin{array}{c}0.08 \\
(0.84)\end{array}$ & $\begin{array}{c}0.05 \\
(0.06)\end{array}$ & $\begin{array}{c}-0.05 \\
(0.06)\end{array}$ \\
\hline$R^{2}$ & 0.13 & 0.11 & 0.03 & 0.21 & 0.09 & 0.16 & 0.13 \\
\hline Clus & 31 & 31 & 22 & 29 & 31 & 30 & 30 \\
\hline Observations & 529 & 535 & 407 & 511 & 520 & 529 & 529 \\
\hline
\end{tabular}

Table B.4: Interaction with Population Density

\begin{tabular}{|c|c|c|c|c|c|c|c|}
\hline \multirow[t]{2}{*}{ Dep. var. } & ATM & Nightligh & s Emp. & $\begin{array}{c}\text { E- } \\
\text { wallet }\end{array}$ & POS & Deposits & Credit \\
\hline & (1) & (2) & (3) & (4) & (5) & (6) & (7) \\
\hline$z_{i, t}$ & $\begin{array}{c}3.08^{* *} \\
(0.84)\end{array}$ & $\begin{array}{l}1.20^{* *} \\
(0.31)\end{array}$ & $\begin{array}{c}0.33^{* *} \\
(0.09)\end{array}$ & $\begin{array}{c}-2.75^{* *} \\
(0.57)\end{array}$ & $\begin{array}{r}-3.04^{*} \\
(1.22)\end{array}$ & $\begin{array}{c}-0.27^{* *} \\
(0.08)\end{array}$ & $\begin{array}{c}0.18^{* *} \\
(0.05)\end{array}$ \\
\hline Interaction & $\begin{array}{c}0.37 \\
(1.95)\end{array}$ & $\begin{array}{c}0.06 \\
(0.84)\end{array}$ & $\begin{array}{c}-0.20 \\
(0.47)\end{array}$ & $\begin{array}{c}1.08 \\
(1.56)\end{array}$ & $\begin{array}{r}7.50^{+} \\
(2.98)\end{array}$ & $\begin{array}{r}-0.38^{*} \\
(0.14)\end{array}$ & $\begin{array}{c}-0.26 \\
(0.21)\end{array}$ \\
\hline$z_{i, t} \times$ Interaction & $\begin{array}{c}0.18 \\
(1.86)\end{array}$ & $\begin{array}{c}0.08 \\
(0.74)\end{array}$ & $\begin{array}{c}-0.22 \\
(0.44)\end{array}$ & $\begin{array}{c}1.01 \\
(1.46)\end{array}$ & $\begin{array}{r}7.71^{+} \\
(2.55)\end{array}$ & $\begin{array}{c}-0.19 \\
(0.10)\end{array}$ & $\begin{array}{r}-0.25 \\
(0.19)\end{array}$ \\
\hline$R^{2}$ & 0.13 & 0.10 & 0.03 & 0.21 & 0.06 & 0.10 & 0.12 \\
\hline Cluster & 31 & 31 & 22 & 29 & 31 & 30 & 30 \\
\hline Observations & 529 & 535 & 407 & 510 & 520 & 528 & 528 \\
\hline
\end{tabular}

\section{B.5 Aggregate Implications}

Figure B.3 reports the actual paths of employment and nightlights and the counterfactual paths implied by the aggregation of our cross-sectional estimates. In each plot, the blue line 
Figure B.3: Counterfactual Employment and Nightlights Employment/Population
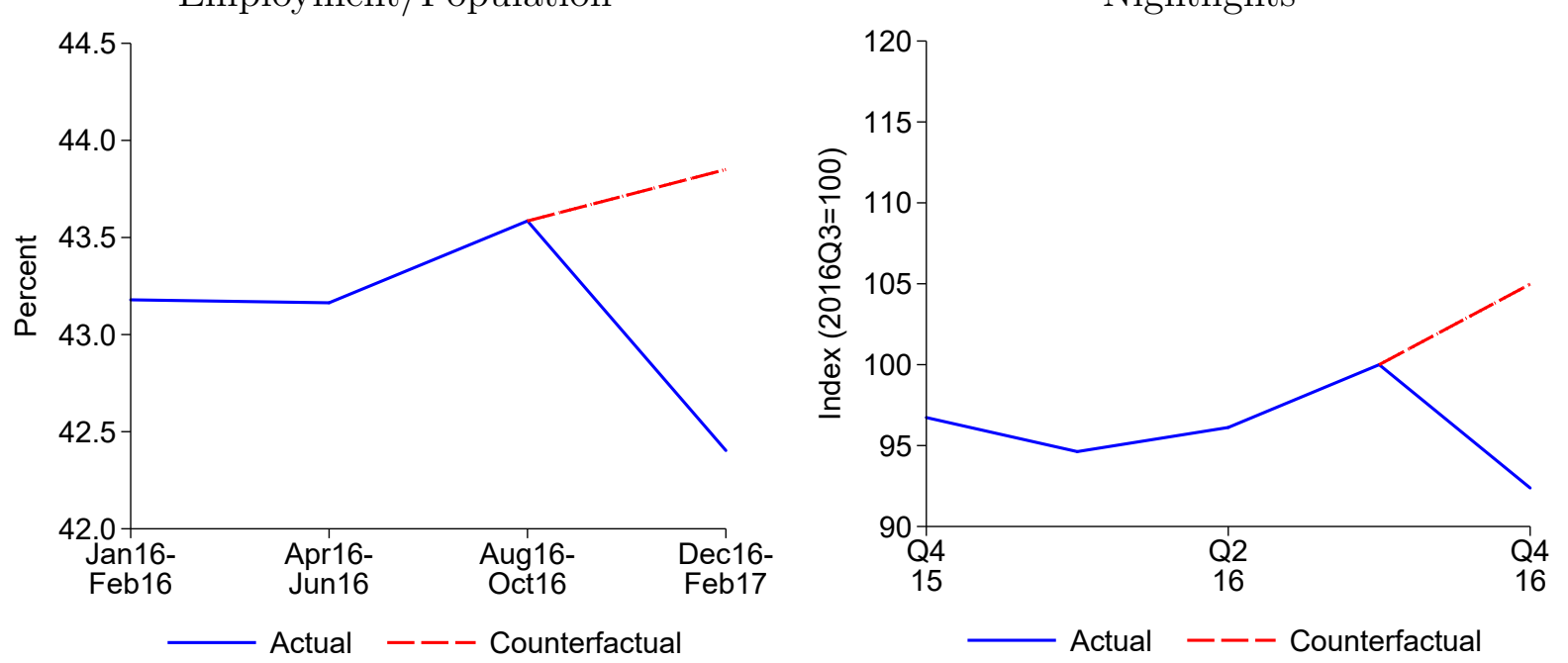

Notes: the blue solid lines in each figure show the time path of actual data. The red dashed lines show the counterfactual time path implied by the aggregation of our cross-sectional estimates.

shows the actual data and the red dashed line the implied counterfactual.

\section{B.6 Measurement Error in the Demonetization Shock}

In this appendix we show that measurement error would attenuate the empirical results toward zero.

Recall our baseline cross-sectional specification:

$$
\Delta y_{i, t}=\beta_{0, t}+\beta_{1, t} z_{i, \text { treatment }}+\Gamma_{t} X_{i}+\epsilon_{i, t}
$$

where $\Delta y_{i, t}=\ln Y_{i, t}-\ln Y_{i, \text { baseline }}$ denotes the change in the natural logarithm of an outcome variable relative to the period before demonetization, $z_{i, \text { treatment }}=\ln Z_{i, \text { treatment }}$ is the $\log$ of the demonetization shock, and $X_{i}$ is a vector containing any controls. We construct $z_{i, \text { treatment }}$ by aggregating across currency chests in district $i$.

Now suppose $z_{i, \text { treatment }}$ is a noisy measure of the true demonetization shock, $z_{i, \text { treatment }}^{*}$,

$$
z_{i, \text { treatment }}=z_{i, \text { treatment }}^{*}+e_{i}
$$

where the measurement error $e_{i}$ is mean zero and independent of $z_{i, \text { treatment }}^{*}$ The measure- 
ment error $e_{i}$ could for example stem from not adjusting for chests serving multiple districts, or from not observing individuals who deposit demonetized notes in banks in other districts to try to circumvent deposit requirements. Thus, the true data generating process replaces $z_{i, \text { treatment }}$ in equation (B.1) with $z_{i, \text { treatment }}^{*}$ :

$$
\Delta y_{i, t}=\beta_{0, t}^{*}+\beta_{1, t}^{*} z_{i, \text { treatment }}^{*}+\Gamma_{t}^{*} X_{i}+\epsilon_{i, t}^{*}
$$

where $E\left[\epsilon_{i, t}^{*} e_{i}\right]=E\left[z_{i, \text { treatment }}^{*} \epsilon_{i, t}^{*} \mid X_{i}\right]=0$.

To study the consequence of estimating equation (B.1) instead of equation (B.3), let $w_{i, t}^{\perp}$ denote the residual from projecting a variable $w_{i}$ on a constant and $X_{i}$ and plim the probability limit. Then the OLS coefficient $\hat{\beta}_{1, t}$ from estimating our baseline specification is:

$$
\begin{aligned}
\operatorname{plim} \hat{\beta}_{1, t} & =\frac{\operatorname{Cov}\left(\Delta y_{i, t}^{\perp}, z_{i, \text { treatment }}^{\perp}\right)}{\operatorname{Var}\left(z_{i, \text { treatment }}^{\perp}\right)} \\
& =\frac{\operatorname{Cov}\left(\Delta y_{i, t}^{\perp}, z_{i, \text { treatment }}^{* \perp}+e_{i}^{\perp}\right)}{\operatorname{Var}\left(z_{i, \text { treatment }}^{* \perp}+e_{i}^{\perp}\right)} \\
& =\frac{\operatorname{Var}\left(z_{i, \text { treatment }}^{* \perp}\right)}{\operatorname{Var}\left(z_{i, \text { treatment }}^{* \perp}+e_{i}^{\perp}\right)} \frac{\operatorname{Cov}\left(\beta_{1, t}^{*} z_{i, \text { treatment }}^{* \perp}+\epsilon_{i, t}^{* \perp}, z_{i, \text { treatment }}^{* \perp}+e_{i}^{\perp}\right)}{\operatorname{Var}\left(z_{i, \text { treatment }}^{* \perp}\right)} \\
& =(1-b) \times \beta_{1, t}^{*},
\end{aligned}
$$

where in the last line we define $b=\operatorname{Var}\left(e_{i}^{\perp}\right) / \operatorname{Var}\left(z_{i, \text { treatment }}^{* \perp}+e_{i}^{\perp}\right) \in[0,1]$ as the attenuation bias coefficient which is the contribution of the measurement error to the overall variance in the measured demonetization shock (after partialling out covariates).

Using equation (B.4), we see that the estimated coefficient from our baseline specification equation (B.1) is equal to the product of $(1-b)$ and the true coefficient $\beta_{1, t}^{*}$. Since $b \in[0,1]$, we have the result that measurement error due to misclassification of flows to currency chests which serve multiple districts or location of deposited notes would bias our results toward zero. The only assumptions made are that the mismeasurement is uncorrelated with the true measure of cash shortage in each district and with the unobserved determinants of the outcome variable.

\section{B.7 Seasonality in CMIE Data}

Insufficient historical coverage (data start in 2016) and the sampling pattern of the CMIE data (not every district surveyed every month) make district-level seasonal adjustment of the 
CMIE data impossible. However, any aggregate seasonal pattern is "differenced out" in the cross-sectional estimation and affects only the constant term in the regression. There remains the issue of district-specific seasonality. Such seasonality is classical left-hand-side measurement error and will inflate the regression standard errors but not bias the point estimates. Formally, let $\Delta s_{i, t}$ denote the (demeaned) district-specific log change in the seasonal factor and $\Delta y_{i, t}^{*}$ (demeaned) seasonally-adjusted employment growth, so that $\Delta y_{i, t}^{*}=\Delta y_{i, t}+\Delta s_{i, t}$ with $E\left[\Delta s_{i, t} z_{i, \text { treatment }}\right]=0$. Comparing the two regression models:

$$
\begin{aligned}
& \Delta y_{i, t}^{*}=\beta_{0, t}^{*}+\beta_{1, t}^{*} z_{i, \text { treatment }}+\Gamma_{t}^{*} X_{i}+\epsilon_{i, t}^{*}, \\
& \Delta y_{i, t}=\beta_{0, t}+\beta_{1, t} z_{i, \text { treatment }}+\Gamma_{t} X_{i}+\epsilon_{i, t},
\end{aligned}
$$

it is apparent that the second equation is equivalent to the first with $\epsilon_{i, t}=\epsilon_{i, t}^{*}-\Delta s_{i, t}$. Therefore, $\operatorname{plim} \hat{\beta}_{1, t}=\operatorname{plim} \hat{\beta}_{1, t}^{*}$, and $\operatorname{Var}\left(\hat{\beta}_{1, t}\right)>\operatorname{Var}\left(\hat{\beta}_{1, t}^{*}\right)$ because the residual variance is larger. 